\title{
A Systematic Modelling Framework for Phase Transfer Catalyst Systems
}

\author{
Anantpinijwatna, Amata; Sales-Cruz, Mauricio; Hyung Kim, Sun ; O’Connell, John P.; Gani, Rafiqul
}

Published in:

Chemical Engineering Research \& Design

Link to article, DOI:

10.1016/j.cherd.2016.07.011

Publication date:

2016

Document Version

Peer reviewed version

Link back to DTU Orbit

Citation (APA):

Anantpinijwatna, A., Sales-Cruz, M., Hyung Kim, S., O'Connell, J. P., \& Gani, R. (2016). A Systematic Modelling Framework for Phase Transfer Catalyst Systems. Chemical Engineering Research \& Design, 115(Part B), 407-422. https://doi.org/10.1016/j.cherd.2016.07.011

\section{General rights}

Copyright and moral rights for the publications made accessible in the public portal are retained by the authors and/or other copyright owners and it is a condition of accessing publications that users recognise and abide by the legal requirements associated with these rights.

- Users may download and print one copy of any publication from the public portal for the purpose of private study or research.

- You may not further distribute the material or use it for any profit-making activity or commercial gain

- You may freely distribute the URL identifying the publication in the public portal 


\section{A Systematic Modelling Framework for Phase Transfer Catalyst Systems}

Amata Anantpinijwatna ${ }^{\mathrm{a}}$, Mauricio Sales-Cruz ${ }^{\mathrm{b}}$, Sun Hyung Kimc, John P. O’Connell ${ }^{\mathrm{d}}$, Rafiqul Gani ${ }^{{ }^{*}}$

${ }^{a}$ Department of Chemical and Biochemical Engineering, Technical University of Denmark, Denmark ${ }^{b}$ Departamento de Procesos y Tecnología, Universidad Autónoma Metropolitana - Cuajimalpa, Mexico

${ }^{c}$ Department of Chemical and Biomolecular Engineering, KAIST, South Korea

${ }^{d}$ Professor Emeritus, University of Virginia, United States

rag@kt.dtu.dk 


\begin{abstract}
Phase-transfer catalyst systems contain two liquid phases, with a catalyst (PTC) that transfers between the phases, driving product formation in one phase and being regenerated in the other phase. Typically the reaction involves neutral species in an organic phase and regeneration involves ions in an aqueous phase. These reacting systems are receiving increased attention as novel organic synthesis options due to their flexible operation, higher product yields, and ability to avoid hazardous or expensive solvents. Major considerations in the design and analysis of PTC systems are physical and chemical equilibria, as well as kinetic mechanisms and rates. This paper presents a modelling framework for design and analysis of PTC systems that requires a minimum amount of experimental data to develop and employ the necessary thermodynamic and reaction models and embeds them into a reactor model for simulation. The application of the framework is made to two cases in order to highlight the performance and issues of activity coefficient models for predicting design and operation and the effects when different organic solvents are employed.
\end{abstract}

\title{
Highlights
}

- Framework for design and analysis of phase transfer catalyst reaction systems.

- Thermodynamic models for prediction of physical and chemical equilibria for phase transfer catalyst systems.

- Model-based solution methods for process design and solvent selection of phase transfer catalyst systems.

\section{Keywords}

- $\quad$ Phase transfer catalyst (PTC)

- Systematic modelling framework for process design

- Solvent selection for phase transfer catalyst system design

- Thermodynamic models for electrolytes in biphasic systems

- Multiphase reaction systems

\section{Nomenclature}

\begin{tabular}{|c|c|}
\hline $\begin{array}{l}\text { Superscripts } \\
0\end{array}$ & Initial value \\
\hline,+- & Cation, anion \\
\hline$\alpha$ & In $\alpha$ phase, usually aqueous \\
\hline$\beta$ & In $\beta$ phase, usually organic \\
\hline Cal & Calculated value from model \\
\hline $\operatorname{Exp}$ & Experimental value \\
\hline Subscripts & \\
\hline$i, k$ & Species \\
\hline$j$ & Reaction \\
\hline$a_{i j}$ & Interaction parameter between group $i$ and $j$ \\
\hline$C_{i}$ & Concentration of species $i$ \\
\hline$\varepsilon_{i j}$ & Order of reaction of species $i$ in reaction $j$ \\
\hline$\xi_{j}$ & Extent of reaction $j$ \\
\hline$F_{i}$ & Molar flow of species $i$ \\
\hline$K_{E q}$ & Equilibrium of reaction \\
\hline$k_{\text {App }}$ & Apparent rate of reaction \\
\hline$k_{j}$ & Rate coefficient of reaction $j$ \\
\hline
\end{tabular}




\begin{tabular}{|c|c|}
\hline$m_{i}$ & Mass of species $i$ \\
\hline$M^{+}$ & Salt Cation \\
\hline$N_{i}$ & Molar amount of species $i$ \\
\hline$\sigma$ & Mean absolute deviation \\
\hline$P_{i}$ & Partition coefficient of species $i$ \\
\hline$q$ & $\begin{array}{l}\text { Surface area parameter of UNIFAC group } \\
\text { Principal PTC Constituent }\end{array}$ \\
\hline$r$ & Volume parameter of UNIFAC group \\
\hline$r_{W s}$ & Standard segment radius \\
\hline$R$ & Principal Reactant Constituent \\
\hline$R_{j}$ & Rate of reaction $j$ \\
\hline$t$ & Time \\
\hline$t_{1 / 2}$ & Half-life of the reaction \\
\hline$t_{E}$ & Equilibrium time of the reaction \\
\hline$V$ & Reactor volume \\
\hline$v_{i j}$ & Stoichiometric number of species $i$ in reaction $j$ \\
\hline$x_{i}$ & Mole fraction of species $i$ \\
\hline$X, X^{-}$ & Reactive Constituent, PTC Anion \\
\hline$Y, Y^{-}$ & Product Constituent, PTC Anion \\
\hline$\gamma_{i}$ & Activity coefficient of species $i$ \\
\hline NRTL & Non-random two-liquid activity coefficient model \\
\hline eNRTL & Electrolyte NRTL activity coefficient model \\
\hline PTC & Phase Transfer Catalyst \\
\hline SAC & Segment activity coefficient model \\
\hline ТВАВ & Tetrabutylammonium bromide \\
\hline TBACN & Tetrabutylammonium cyanide \\
\hline UNIFAC & UNIQUAC functional-group activity coefficient model \\
\hline UNIQUAC & Universal quasichemical activity coefficient model \\
\hline
\end{tabular}

\section{Introduction}

Phase transfer catalytic (PTC) systems, involving aqueous and organic phases, can be useful for chemical processes where part of an organic reactant exchanges with an ionic or polar species, since solubility limitations will inhibit reactive contact in a single phase. The principle is for a catalyst with substantial nonpolar character to react with the ionic or polar species in the aqueous phase and then transfer to the organic phase as a neutral species to combine with the organic reactant.

The first known commercial use of a PTC system was reported by Rueggeberg et al. (1946), for the production of benzyl benzoate from benzyl chloride and sodium benzoate catalysed with diethyl- and triethylamines as PTC. Since then, the approach has been applied to various types of organic synthesis opening novel reaction routes and allowing selection of faster and/or cheaper catalysts. Some important examples include active ion transfer systems where active quaternary ammonium salts are transferred as from an aqueous phase to allow substitutions for the oxidation of olefins, the borohydride reduction of ketones, the hydrolysis of esters, and cyanide displacement processes (Starks, 1971; 1973; Chandler et al., 1998). In addition, there are oxidising agent transfer systems where the transferred species catalyse reactions in the organic phase, such as alkyl chloride and nitrile formation, and benzoin condensation (Dehmlow, 1974; Rozwadowska, 1985). Finally, in free-radical assisted reactions, the PTC carries or creates free radical species for enhancing product properties or avoiding hazardous chemicals and severe reaction condition for halogenation, polymerization, and alkylation reactions (Kolvari et al., 2007; Kaur et al., 2011; de Zani and Colombo, 2012). These cases demonstrate that PTC systems allow flexible and easier operation, 
yield higher production, and, while not eliminating added solvents, can avoid those which may be hazardous or expensive.

The biphasic PTC system of focus in this paper contains two completely immiscible liquid phases created by water and an organic compound. The PTC transfers as an active species from one phase to the other in order to convert the reactant to the desired product and then transferring as an inactive species back to be regenerated in the aqueous phase. Here, as shown in Figure 1, the desired reaction is to form the product RY from the reactant $\mathrm{RX}$. The PTC is identified as $\mathrm{Q}$, which in the aqueous phase is a positively charged cation $\left(\mathrm{Q}^{+}\right)$, such as tetraalkylammonium, coexisting with anions $\left(\mathrm{X}^{-}\right.$or $\left.\mathrm{Y}^{-}\right)$. In the organic phase the PTC is in a neutral form (active $\mathrm{QY}$ and inactive QX). The reaction occurs in the organic phase with RY going to the desired RX while QY goes to QX. Then the inactive PTC (QX) transfers to the aqueous phase and ionizes. The added salt $\left(\mathrm{M}^{+} \mathrm{X}^{-}\right)$reforms the active PTC $\left(\mathrm{Q}^{+} \mathrm{X}^{-}\right)$to transfer back to the organic phase, forming a spent salt product $\left(\mathrm{M}^{+} \mathrm{Y}^{-}\right)$.

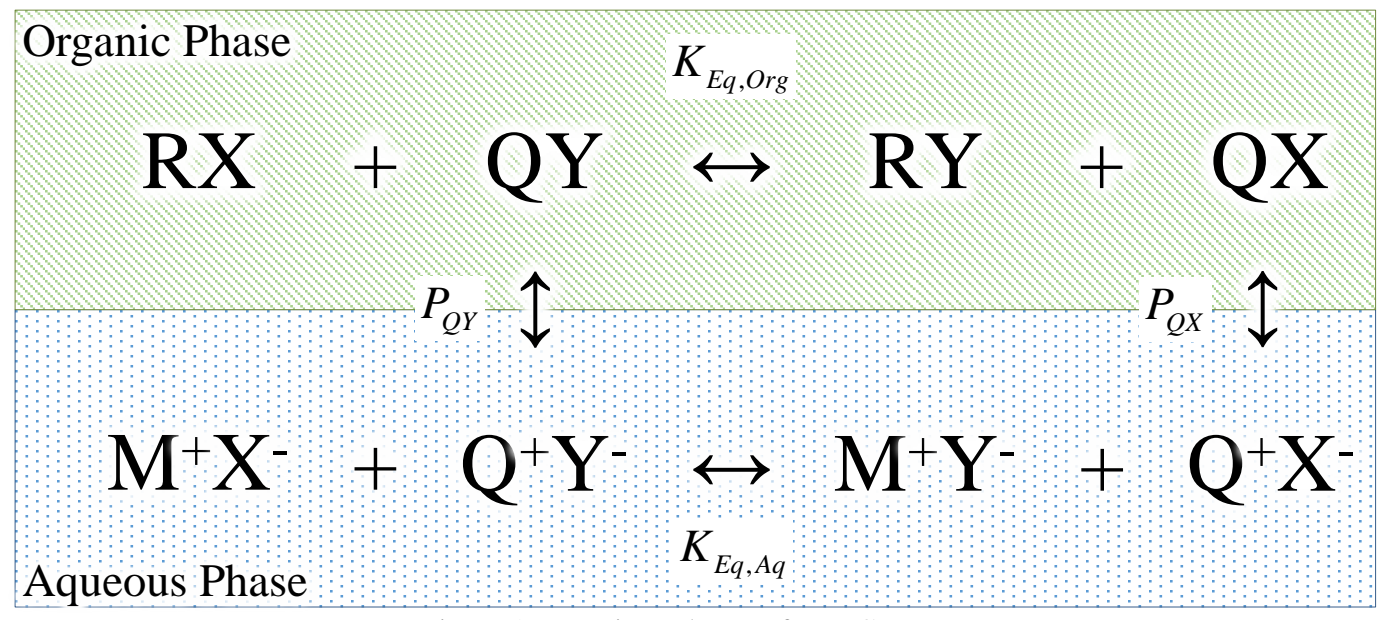

Figure 1: Reaction scheme of a PTC system

Process design and analysis via simulation require mathematical models to describe the physical and chemical equilibria and rate behaviour of a system. Here, the model-based design-analysis tool must deal with the reaction kinetics and equilibria in two coexisting liquid phases, as well as estimate partitioning of many chemical species (solvents, reactants, products, and PTC). Further, the modelling is often complicated by a lack of experimental data. Previously, a simple data-based model was reported by Samant et al. (2001) for the design of PTC systems. Piccolo et al. (2012) proposed a model-based framework for the design of reacting systems with phase transfer catalysis, where they successfully used models for partition coefficients of species in the two co-existing phases to predict the distributed amounts of PTCs. The main limitation of their model-based framework was the limitation to chemical systems for which the model parameters had been obtained. In addition, several other models involving tetraalkylammonium ions in PTC systems with limited application range have been developed (Belvèze et al., 2004; Papaiconomou et al., 2012; Jaime-Leal et al., 2014; Najibi et al., 2015). An early and abbreviated version of the current work was reported by Anantpinijwatna, et al. (2014).

In the present paper, a systematic biphasic modelling framework, applicable to a wider range of PTC systems than previously reported, is presented together with new applications that highlight the use of newly developed models. While some experimental data are still required, our framework now extends the early version, and includes significant predictive elements. In what follows, Section 2 presents the framework and procedure for obtaining the various models for constructing a PTC based reactor model. Details are given for several thermodynamic models implemented in the framework: NRTL, eNRTL, SAC, e-KT-UNIFAC. In section 3, models of two biphasic reaction systems are formulated according to the framework. In section 4, the models are applied to find the PTC-solvent pairs with the highest product yield, minimum impurities, and fastest overall reaction rate. Also, performances of the thermodynamic models are evaluated by comparison with available data. For each of these models in the examples, the corresponding model parameters have been identified. 


\section{The Framework and Constitutive Models}

\subsection{Systematic Biphasic Modelling Framework}

Our biphasic modelling framework is developed based on the systematic model generation method of Cameron and Gani (2011). The structure of the procedure is shown in Figure 2. The process starts with defining the modelling objectives, followed by model construction, analysis, and solution by a derived numerical solution strategy. The model equations are classified in terms of balances, constitutive relations, and conditions.

The first step in the process is to collect information on the reactive system. The chemical species are separated into homogeneous species, remaining in only one phase, and heterogeneous species, distributing/partitioning into both phases. Next, they are classified in terms of solvent, reactive (reactant and product), and inert species, noting that dissociation of chemical species into ions is considered only for the aqueous phase. Also, pure species physicochemical properties, such as vapour pressure, density, viscosity, Gibbs energy and enthalpy of formation leading to reaction equilibrium constants, and melting and boiling temperatures are retrieved from a database or estimated by an appropriate group contribution method (e.g., Constantinou and Gani, 1994).

Next, constitutive equations are collected by selecting the appropriate property models for activity coefficients, which are used for computing species partitioning and equilibrium extents of reaction. Then, the reactions are classified into those that are kinetically controlled, those that are equilibrium controlled, and those that are mixed. If mass transfer of heterogeneous chemical species between phases is not instantaneous, mass transfer effects are also considered, usually within the kinetic formulation.

Finally, from the reaction system information and the reactor type (CSTR, batch or fed-batch), mass balance equations are generated, along with conditional equations such as the definitions of mole fraction and/or the condition of equilibrium.

In the present formulation, the constitutive and conditional equations are developed in modules which depend on the PTC system and modelling objectives. The final result is a problem-specific model that arises from the combination of the three classes of equations. We now describe generic equations and details of the steps of each module for equation selection and model generation. 


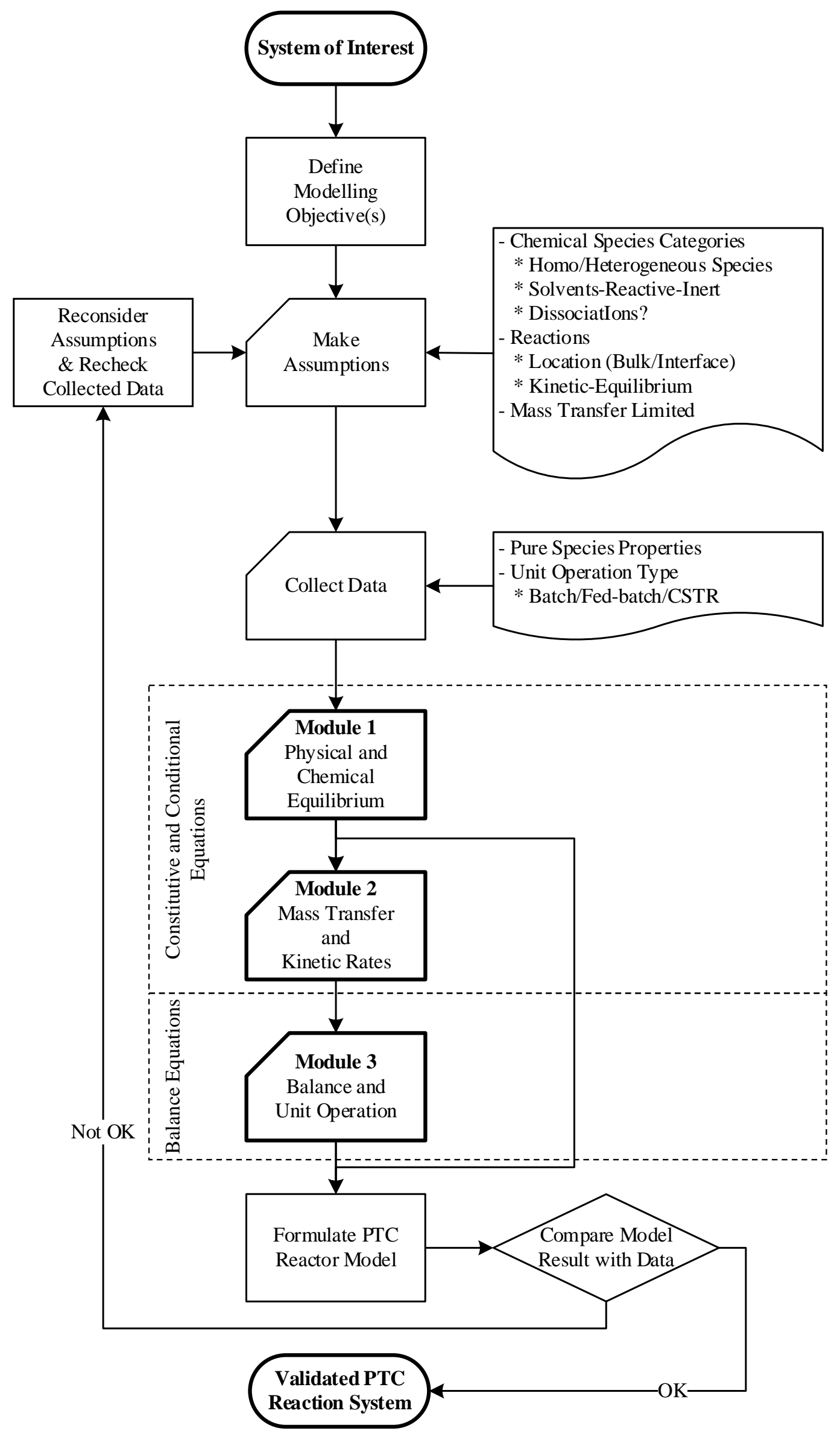

Figure 2: Framework for modelling biphasic PTC reaction systems 
Module 1 is where the physical and chemical equilibrium equations are developed. In particular, the partition coefficient is defined as the distribution of each heterogeneous species between the two co-existing phases, and is given by equations 1 and 2 .

$$
\begin{gathered}
P_{i}=\frac{\gamma_{i}^{\alpha}}{\gamma_{i}^{\beta}} \\
x_{i}^{\alpha} P_{i}=x_{i}^{\beta}
\end{gathered}
$$

where $P_{i}$ is the partition coefficient of species $i$ between the phases $\alpha$ and $\beta$; $\gamma_{i}^{\alpha}$ and $\gamma_{i}^{\beta}$ are the activity coefficients of species $i$ in phases $\alpha$ and $\beta ; x_{i}^{\alpha}$ and $x_{i}^{\beta}$ are the mole fractions of species $i$ in phases $\alpha$ and $\beta$, respectively.

The chemical equilibrium constant is related to the standard Gibbs energy of formation by equation 3.

$$
K_{E q, j}=\exp \left(-\frac{\Delta G_{j}}{R T}\right)
$$

where $K_{E q, j}$ is the chemical equilibrium constant of reaction $j, \Delta G_{j}$ is the standard Gibbs free energy change for the reaction $j, R$ and $T$ are the universal gas constant and temperature respectively.

The detailed steps taken in Module 1 are shown in Figure 3a, the heterogeneous species are paired with the solvents into sub-systems. The activity coefficients $\left(\gamma_{i}^{\alpha}\right.$ and $\gamma_{i}^{\beta}$ ) of each sub-system are calculated from a chosen thermodynamic model. The model parameters must either be obtained by regression of experimental data or estimated from chemical structures. The intention is to develop a model with parameters that can be used for multiple systems. 


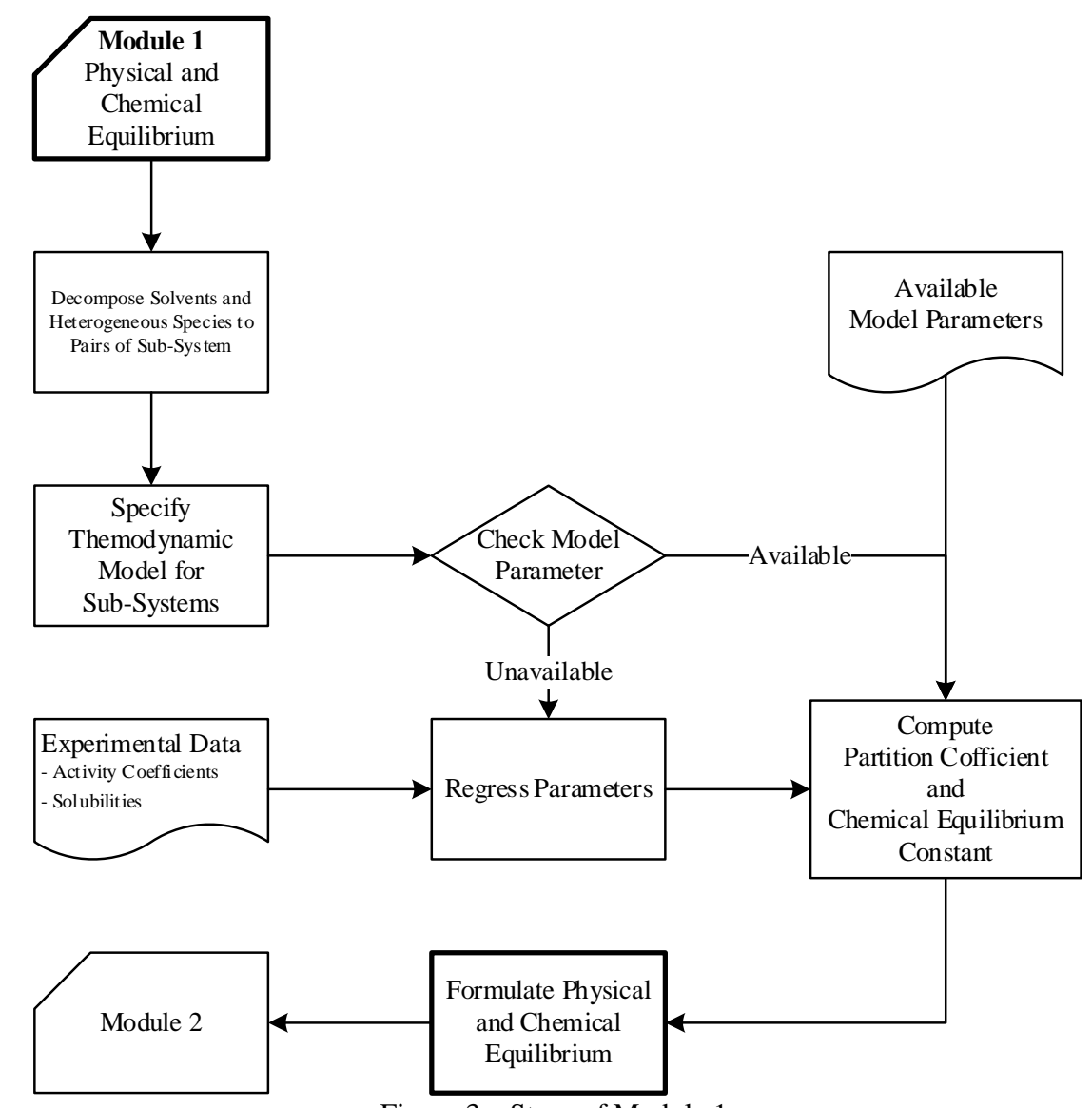

Figure 3a: Steps of Module 1

Module 2 is where the reaction mechanisms and mass transfer description are established. We formulate the generic reaction model from the non-elementary reaction rate law given in Equation 3.

$$
R_{j}=k_{j}\left(\prod_{i}\left(C_{i} \gamma_{i}\right)^{\varepsilon_{i j}}-\frac{\prod_{i}\left(C_{i} \gamma_{i}\right)^{\varepsilon_{i j}^{<}}}{K_{E q, j}}\right)
$$

where $R_{j}$ is the rate of reaction $j ; C_{i}$ is the concentration of species $i ; \gamma_{i}$ is the activity coefficient of species $i$; $k_{j}$ is the forward rate constant of reaction $j ; K_{E q, j}$ is the equilibrium constant of reaction $j ; \varepsilon_{i j}^{>}$and $\varepsilon_{i j}^{<}$are the orders of reaction of species $i$ in reaction $j$ for the forward and backward reactions, respectively.

Note that if the reaction may be considered to occur at the interface a third phase is included. In the case of a purely kinetically-driven forward reaction, the term $\left(\frac{\prod_{i}\left(C_{i} \gamma_{i}\right)^{\varepsilon_{i j}^{<}}}{K_{E q, j}}\right)$ is omitted, while if the equilibrium is rapidly achieved the rate of reaction is set to zero. For diffusion across interfaces, a mass transfer coefficient, $k_{L}$, is substituted for $k_{j}$ and the mole fraction difference between phases, based on the partition coefficient $\left(P_{i}\right)$ from module 1 is used equivalent to the forward rate of reaction. The kinetic parameters are obtained by regressing experimental transient concentration data. The detailed steps taken in Module 2 are shown in Figure 3b. 


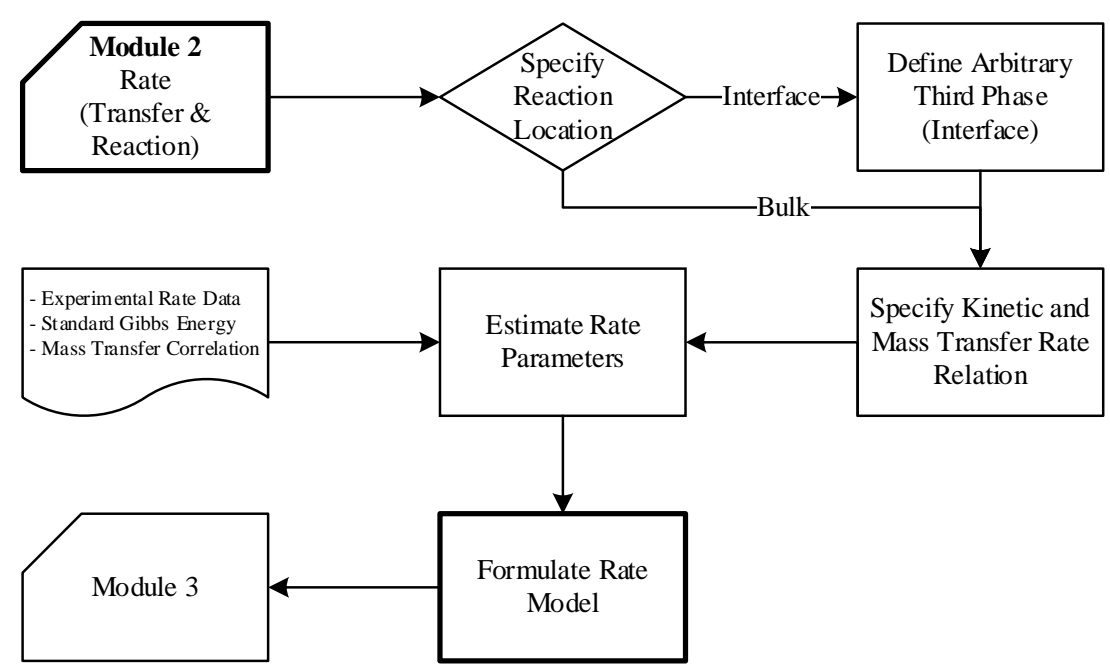

Figure 3b: Steps of Module 2

Module 3 is where the balance equations that depend on the reactor geometry and the biphasic description are established. The generic mass balance equation is related with other modules through the extent of reaction concept, as given by equations 4 and 5 .

$$
\begin{aligned}
& \frac{d \xi_{j}}{d t}=R_{j} V \\
& N_{i}^{\alpha}=N_{i}^{0}+\sum_{j} v_{i j} \xi_{j}+F_{i}^{0}-F_{i}-N_{i}^{\beta}
\end{aligned}
$$

where $\xi_{j}$ is the extent of reaction $j$ as a function of time and rate of reaction; $N_{i}^{\alpha}$ is the molar amount of species $i$ in phase $\alpha, N_{i}^{0}$ is the initial amount of species $i ; N_{i}^{\beta}$ is the amount of species $i$ in phase $\beta$ for heterogeneous species; $v_{i j}$ is the stoichiometric coefficient for species $i$ in reaction $j ; F_{i}$ and $F_{i}{ }^{0}$ are the reactor inlet and outlet flows of species $i$, respectively; these are zero for a batch reactor.

For dissociating species, the balance module includes equations 6 and 7, in order to initialize the amounts of dissociated cationic and anionic species, $N_{i+}^{0}$ and $N_{i-}^{0}$.

$$
\begin{aligned}
& N_{i^{+}}^{0}=\sum_{k} N_{i^{+} k}^{0} \\
& N_{i^{-}}^{0}=\sum_{k} N_{k i^{-}}^{0}
\end{aligned}
$$

where $N_{i^{+} k}^{0}$ is an initial molar amount of a dissociable component $i^{+} k$ with $i^{+}$cation and $k$ anion and $N_{k i^{-}}^{0}$ is an initial molar amount of a dissociable component $\mathrm{ki}^{-}$with $k$ cation and $i^{-}$anion species.

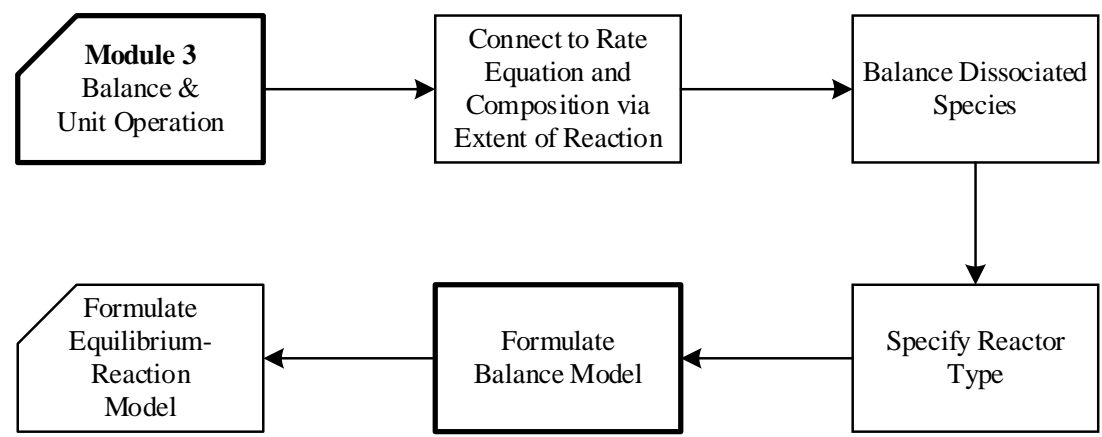

Figure 3c: Steps of Module 3 
After the model consisting of equations from the three modules has been generated, it is advisable to validate it using available data before further use in design and analysis of a PTC system. If the model fails the validation test, the model parameters may be fine-tuned with additional data.

\subsection{Constitutive Thermodynamic Model Implementation}

Vital information for reliable and innovative design of a PTC-based process is the partitioning of the active and inactive forms of the PTC and other species between them. We decompose the list of species into four subsystems $(A-D)$ and list the property models used for each.

Subsystem A (organic solvent - water) deals with the mutual solubilities of the organic solvent with water. The models are NRTL, NRTL-SAC, or KT-UNIFAC.

Subsystem $B$ (inorganic salt - water) treats the behaviour of the inorganic salt $\left(\mathrm{M}^{+} \mathrm{X}^{-}\right.$and $\left.\mathrm{M}^{+} \mathrm{Y}^{-}\right)$in the aqueous phase using the e-NRTL, e-NRTL-SAC, or e-KT-UNIFAC models.

Subsystem $C$ (organic solvent - PTC) considers the PTC neutral species (QX and QY) in the organic solvent with the NRTL, NRTL-SAC, UNIFAC-IL, or e-KT-UNIFAC models.

Subsystem $D$ (water - PTC) describes the behaviour of the ionized PTC species $\left(\mathrm{Q}^{+} \mathrm{X}^{-}\right.$and $\left.\mathrm{Q}^{+} \mathrm{Y}^{-}\right)$in the aqueous phase with the e-NRTL, e-NRTL-SAC, or e-KT-UNIFAC models.

The model descriptions of subsystem $A$ are satisfactory using with existing models, but a new electrolyte model (e-KT-UNIFAC, Kim et al., 2016) has been developed and applied here to subsystem B (Kim et al., 2016)(Kim et al., 2016)(Kim et al., 2016)(Kim et al., 2016)(Kim et al., 2016)(Kim et al., 2016) for some representative alkali halide salts that are donors of reacting anions or acceptors of inactive anions.

Combinations of different appropriate thermodynamic models for subsystems $C$ and $D$ have been applied to calculate the partitioning of the PTC between the aqueous and organic phases. For example, the solubilities of various PTC species in different organic solvents of subsystem $C$ can be determined using the NRTL, NRTLSAC, and e-KT-UNIFAC models with newly fitted parameters, as reported in this section. Behaviours of the PTC in the aqueous phase of subsystem $D$ can also be predicted using the eNRTL, eNRTL-SAC, and e-KT-UNIFAC models with newly fitted parameters. Table 1 tabulates the models for each subsystem.

Table 1: Thermodynamic Constitutive Models for Species Subsystems

\begin{tabular}{|c|c|c|}
\hline Subsystem & Model & Model Type \\
\hline$A$ & NRTL & Correlative \\
\hline \multirow[t]{3}{*}{ (organic solvent - water) } & NRTL-SAC & Partially Predictive \\
\hline & UNIQUAC & Correlative \\
\hline & UNIFAC & Predictive \\
\hline \multirow{3}{*}{$\begin{array}{l}B \\
\text { (inorganic salt - water) }\end{array}$} & eNRTL & Correlative \\
\hline & eNRTL-SAC & Partially Predictive \\
\hline & e-KT-UNIFAC & Predictive \\
\hline \multirow{4}{*}{$\begin{array}{l}C \\
\text { (organic solvent - PTC) }\end{array}$} & NRTL & Correlative \\
\hline & NRTL-SAC & Partially Predictive \\
\hline & UNIFAC-IL & Predictive \\
\hline & e-KT-UNIFAC & Predictive \\
\hline \multirow{3}{*}{$\begin{array}{l}D \\
\text { (water - PTC) }\end{array}$} & eNRTL & Correlative \\
\hline & eNRTL-SAC & Partially Predictive \\
\hline & e-KT-UNIFAC & Predictive \\
\hline
\end{tabular}

\subsubsection{The NRTL and eNRTL Models}

Piccolo et al. (2012) proposed using a combination of the NRTL and eNRTL models for subsystems $C$ and $D$ respectively. The applicability of this combination is limited by the need for experimental data of each pair of PTC with solvent and PTC with water. Due to the specific interaction parameter of required for each system, this approach is less useful for prediction, but has lower uncertainty because the parameter is fitted to data. We use this combination for the benzoin condensation case study of Section 3.1 with the results given in section 4.1. 


\subsubsection{The Segment Activity Coefficient (SAC) Models}

The non-random two-liquid segment activity coefficient (NRTL-SAC) and its extension for electrolyte systems (eNRTL-SAC) were proposed by Chen and co-workers (2004; 2005; 2009). The NRTL-SAC model has been successfully applied for calculating solubilities of complex molecules in organic solvents, while the eNRTL-SAC model has been applied for activity coefficient calculations of various electrolytes. The models divide a molecule into conceptual segments (four segments for NRTL-SAC and five segments for eNRTL-SAC) with the segments having specific values for interactions between them. Thus, this model is predictive for the systems with known solvents and PTCs. Application to new PTCs requires experimental data to estimate the number of segments, though if determined for one system, it can be employed for any known solvent.

We have applied the NRTL-SAC to subsystem $C$ and the eNRTL-SAC to subsystem $D$. Since segment numbers are not known for tetraalkylammonium PTC in Subsystem C, we have regressed the parameters to experimental data from Yu and Friedman (1966), Frank and Clarke (1967), Abraham and co-workers (1970; 1971; 1972; 1973; 1983; 2001), Talukdar and Kundu (1991), and Lee and Huang (2002). In total, 63 binary systems in 12 organic solvents, with 65 experimental points were used. The regressed segment numbers are given in Table 2 and graphical comparison of model calculation and measured data is shown in Figure 4. Within the 12 solvents, the calculated solubilities of PTC in benzene, bromobenzne, chloroform, toluene, cyclohexane, dichloromethane, hexane, and 1,1- and 1,2- dichloroethane are deviated less than $5 \%$ from the measured data. Only the calculated solubilities of tetraethyl and tetrapropyl ammonium iodide PTC in ethyl acetate, ethyl ether, and chlorobenzene deviate greatly from the measured data.

Table 2: Segments numbers for subsystem C of PTC systems

\begin{tabular}{|c|c|c|c|c|c|}
\hline \multirow[t]{2}{*}{$\overline{\text { PTC }}$} & \multicolumn{4}{|c|}{ Segment Number } & \multirow[t]{2}{*}{$\sigma^{*}$} \\
\hline & $\mathrm{X}$ & Y- & $\mathrm{Y}+$ & $\mathrm{Z}$ & \\
\hline $\mathrm{Me}_{4} \mathrm{NBr}$ & 0.074 & 0.003 & 0.106 & 0.057 & 0.00 \\
\hline $\mathrm{Me}_{4} \mathrm{NCl}$ & 2.908 & 3.863 & 0 & 2.787 & 0.00 \\
\hline $\mathrm{Me}_{4} \mathrm{NI}$ & 0 & 0 & 0 & 2.506 & 0.66 \\
\hline $\mathrm{Et}_{4} \mathrm{NBr}$ & 0.924 & 1.344 & 0 & 1.17 & 0.01 \\
\hline $\mathrm{Et}_{4} \mathrm{NCl}$ & 1.113 & 0.039 & 0 & 0.189 & 0.00 \\
\hline $\mathrm{Et}_{4} \mathrm{NI}$ & 0 & 1.287 & 1.862 & 2.101 & 0.81 \\
\hline $\mathrm{Pr}_{4} \mathrm{NBr}$ & 0.028 & 2.07 & 0 & 0.01 & 0.00 \\
\hline $\mathrm{Pr}_{4} \mathrm{NI}$ & 0.496 & 2.088 & 0 & 0.513 & 0.06 \\
\hline $\mathrm{Bu}_{4} \mathrm{NBr}$ & 2.346 & 0 & 0 & 0.981 & 0.33 \\
\hline $\mathrm{Bu}_{4} \mathrm{NCl}$ & 0.046 & 2.915 & 0 & 0.547 & 0.41 \\
\hline $\mathrm{Bu}_{4} \mathrm{NI}$ & 0.074 & 0.003 & 0.106 & 0.057 & 0.00 \\
\hline
\end{tabular}

$$
{ }^{*} \sigma=100\left(\sum_{i=1}^{N}\left|1-X_{\text {Sat }, i}^{\text {Cal }} / X_{\text {Sat }, i}^{\text {Exp }}\right|\right) / N
$$




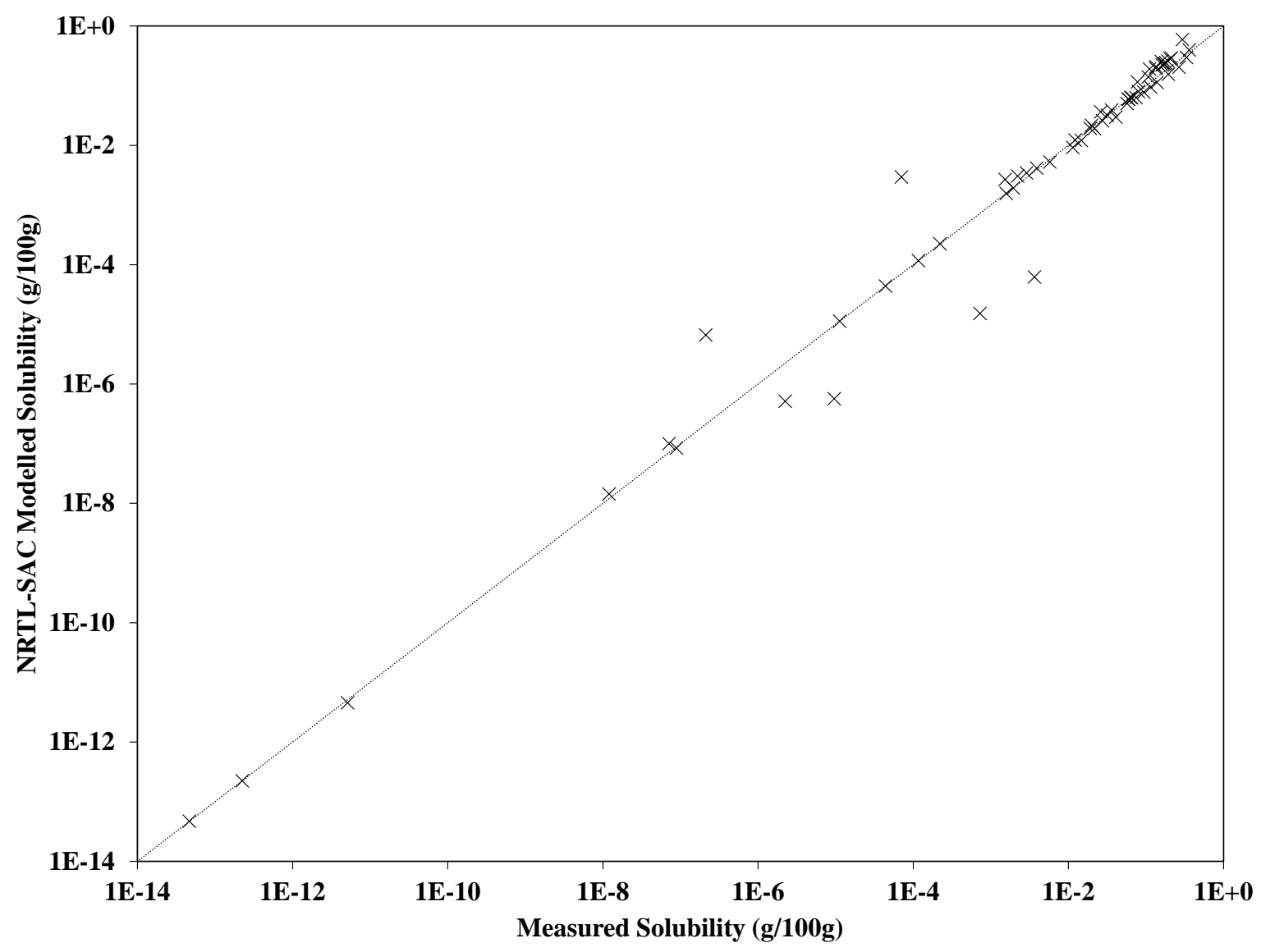

Figure 4: Comparison of Experimental and NRTL-SAC Fitted Tetraalkylammonium PTC solubilities in organic solvents.

The subsystem $D$ of PTC with water is modelled with the eNRTL-SAC model. In order to regress the segment numbers for the eNRTL-SAC model, data from Lindenbaum, et al. (1964; 1966; 1970), and Wen et al. (1966) have been used. In total, there exist 470 experimental data points from 24 binary systems. The regressed segment numbers of tetraalkylammonium PTC are shown in Table 3. Graphical comparisons of activity coefficients for only (methyl to butyl) tetraalkylammonium bromide and chloride are shown in Figure 5, while Figure 6 comparisons of model calculation and data for all available PTC-water measurements. 
Table 3: Segments numbers for subsystem D of PTC systems

\begin{tabular}{|c|c|c|c|c|c|c|c|}
\hline \multicolumn{2}{|c|}{ PTC } & \multicolumn{5}{|c|}{ Segment Numbers } & \multirow{2}{*}{$\sigma$} \\
\hline Cation & Anion & $\mathbf{X}$ & Y- & $\mathbf{Y}+$ & $\mathbf{Z}$ & $\mathbf{E}$ & \\
\hline \multirow{5}{*}{$\mathrm{Me}_{4} \mathrm{~N}$} & $\mathrm{Br}$ & 0 & 0 & 1.144 & 1.301 & 0.986 & $1.03 \mathrm{E}-04$ \\
\hline & Cl & 0 & 4.242 & 4.267 & 0 & 0.220 & 5.80E-03 \\
\hline & I & 0 & 0 & 1.519 & 0.018 & 1.049 & $2.14 \mathrm{E}-05$ \\
\hline & $\mathbf{O H}$ & 0.099 & 3.391 & 1.831 & 0.018 & 1.015 & 6.34E-08 \\
\hline & Ac & 0.171 & 2.390 & 0.937 & 2.142 & 1.029 & 3.82E-07 \\
\hline \multirow{5}{*}{$\mathrm{Et}_{4} \mathrm{~N}$} & $\mathrm{Br}$ & 0 & 2.067 & 3.545 & 0 & 0.730 & $2.56 \mathrm{E}-03$ \\
\hline & CI & 0.626 & 3.744 & 0 & 0 & 0.162 & $1.04 \mathrm{E}-02$ \\
\hline & I & 0.166 & 0.131 & 1.549 & 0.018 & 1.091 & 5.00E-05 \\
\hline & $\mathbf{O H}$ & 0.422 & 3.260 & 0 & 0.018 & 0.963 & 3.52E-06 \\
\hline & Ac & 0 & 1.545 & 0.503 & 0.018 & 1.076 & $6.02 \mathrm{E}-06$ \\
\hline \multirow{5}{*}{$\mathrm{Pr}_{4} \mathrm{~N}$} & $\mathrm{Br}$ & 0.462 & 0.486 & 0.414 & 3.216 & 1.048 & $6.17 \mathrm{E}-05$ \\
\hline & Cl & 0 & 0.015 & 0 & 0 & 1.502 & $1.65 \mathrm{E}-03$ \\
\hline & I & 0 & 0 & 2.773 & 0 & 1.137 & 4.10E-06 \\
\hline & $\mathbf{O H}$ & 0 & 1.366 & 0 & 3.896 & 1.108 & $1.57 \mathrm{E}-05$ \\
\hline & Ac & 0.063 & 2.332 & 1.581 & 0.144 & 1.025 & $8.11 \mathrm{E}-08$ \\
\hline \multirow{2}{*}{$\mathrm{Bu}_{4} \mathbf{N}$} & $\mathrm{Br}$ & 0.077 & 0 & 1.770 & 0.529 & 0.794 & 7.17E-03 \\
\hline & Cl & 0 & 0 & 0.433 & 1.426 & 0.868 & $1.76 \mathrm{E}-03$ \\
\hline \multirow{2}{*}{$\mathrm{C}_{11} \mathrm{H}_{17} \mathrm{NO}$} & $\mathrm{Br}$ & 0.107 & 0 & 2.066 & 0.077 & 0.883 & $3.88 \mathrm{E}-03$ \\
\hline & $\mathrm{Cl}$ & 0 & 0 & 1.680 & 0.294 & 0.938 & 2.19E-04 \\
\hline \multirow{2}{*}{$\mathrm{C}_{5} \mathrm{H}_{14} \mathrm{NO}$} & $\mathrm{Br}$ & 0 & 0 & 1.232 & 0.921 & 1.020 & $2.44 \mathrm{E}-04$ \\
\hline & $\mathrm{Cl}$ & 0 & 0 & 0.699 & 0.480 & 1.088 & $9.09 \mathrm{E}-06$ \\
\hline \multirow{2}{*}{$\mathrm{BzMe}_{3} \mathrm{~N}$} & $\mathrm{Br}$ & 0.015 & 0 & 2.228 & 0 & 0.919 & $1.89 \mathrm{E}-03$ \\
\hline & Cl & 0 & 0 & 1.390 & 0 & 1.010 & 7.80E-05 \\
\hline $\mathrm{C}_{8} \mathrm{H}_{21} \mathrm{NO}_{5}$ & $\mathrm{Br}$ & 0 & 0 & 1.431 & 0.662 & 0.985 & 3.77E-04 \\
\hline
\end{tabular}

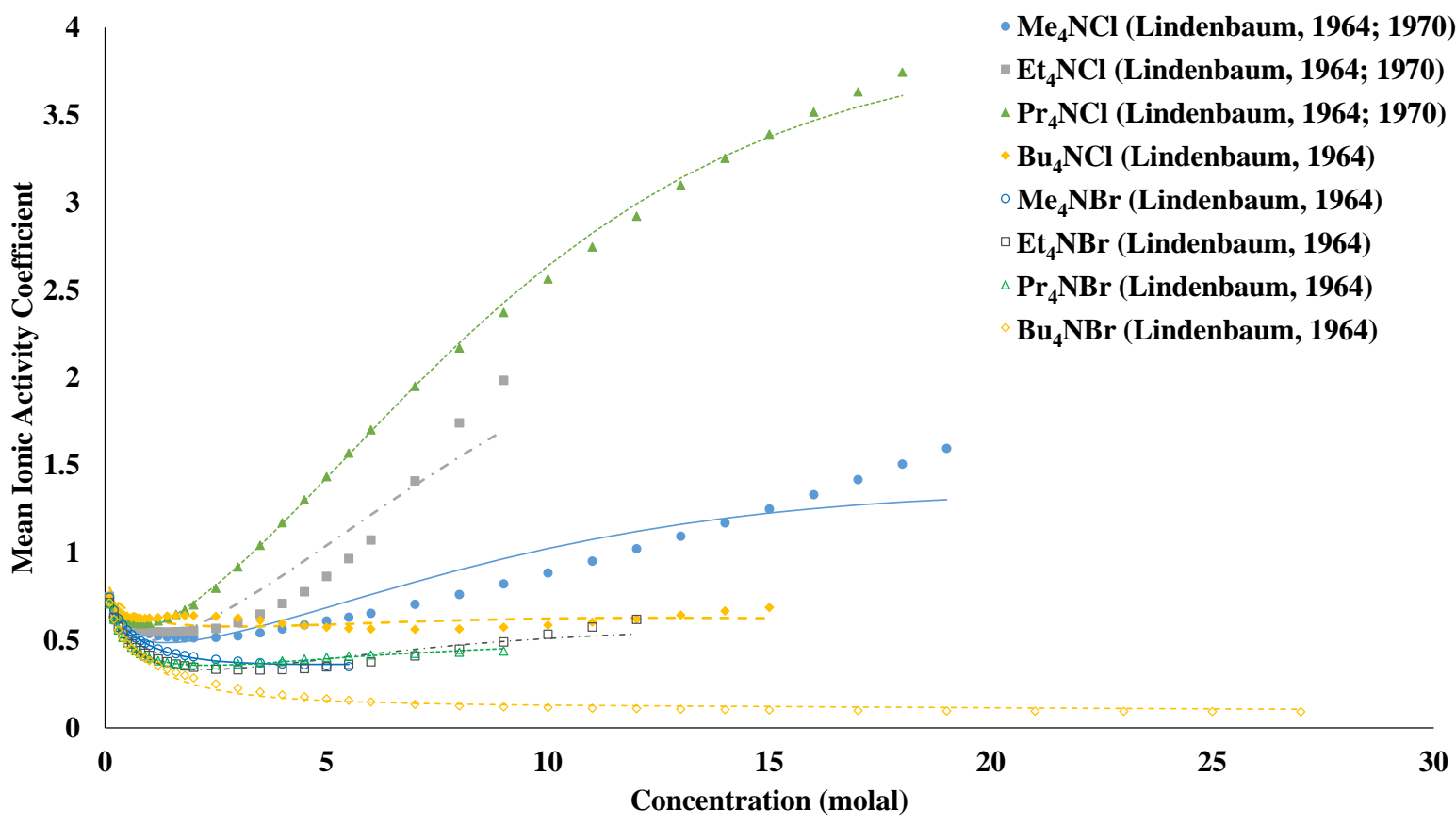

Figure 5:, Comparison of eNRTL-SAC Model Calculations of Mean Ionic Activity Coefficients of Tetraalkylammonium Bromide and Chloride PTC. 


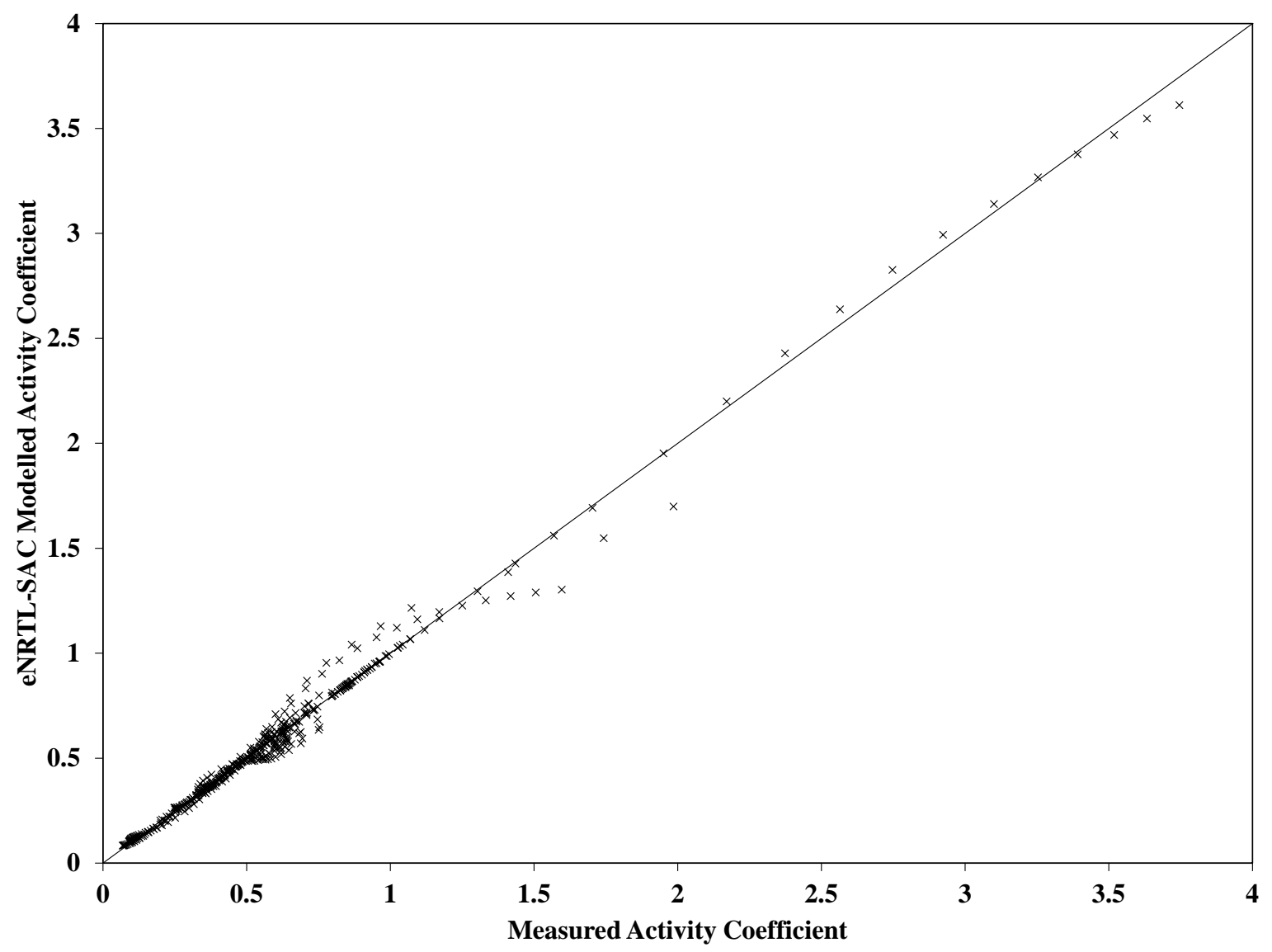

Figure 6: Comparison of eNRTL-SAC Model Calculations of Mean Ionic Activity Coefficients of Tetraalkylammonium Bromide and Chloride PTC.

\subsection{3 e-KT-UNIFAC Model}

The e-KT-UNIFAC is a new extension of the KT-UNIFAC model of Kang, et al. ( 2002) for correlation and prediction of electrolyte solution thermodynamic properties. The model combines the terms for Debye-Hückel theory, second virial coefficients, and the short-range KT-UNIFAC effects to account for binary interactions between ions with ions and ions with groups (Kim et al., 2016). The approach has been successfully applied for prediction of alkali halide phase behaviour in aqueous and mixed solvent systems. We have applied this model to subystems B, C, and D.

Here, the PTCs are considered as chains of UNIFAC groups attached to a central ion group ( $N^{+}$). The volume $r_{i}$ surface area $q_{i}$ and interaction $\left(a_{i j, 1}\right.$ and $a_{i j, 2}$ ) parameters, are obtained from the original KT-UNIFAC model, when available.

Structural and interaction parameters of halide ions are given by Kim et al. (2016). Thus, only the $N^{+}$group has new parameters for our purposes. Using ionic radii selected by Marcus (2008), and the same standard segment radius as in previous work $\left(r_{W s}=1.0 \AA\right)$, structural parameters of the $N^{+}$group can be obtained. The same set of experimental data as in Section 2.2.2, together with the new data for asymmetric and isomer PTC reported by Blanco, et al. (2005; 2006; 2008; 2009) have been used for regressing the interaction parameters for the $N^{+}$ group and others in our systems. In total, 763 data points were used. All new parameters are reported in Table 4. Figure 7 compares activity coefficients from the model with data for all the available data points; the average deviation is $1.07 \%$. Figure 8 compares model and measured solubilities; the average deviation is $1.48 \%$.

The e-KT-UNIFAC gives about the same error in predicting activity coefficients of the PTCs in the aqueous phase as the eNRTL-SAC (1.07\% for e-KT-UNIFAC vs. 1.04\% for eNRTL-SAC). Since experimental uncertainties have not been reported, but we believe that the model agreement is very good. Note that the e-KT-UNIFAC is 
more accurate for solubility estimates in the organic phase than the NRTL-SAC model (1.48\% to $5.21 \%)$ and in addition, since e-KT-UNIFAC is a group contribution approach, it can be fully predictive for other species.

Table 4: e-KT-UNIFAC model parameters for PTC systems

\begin{tabular}{|c|c|c|c|c|c|}
\hline \multicolumn{2}{|l|}{ Group } & \multicolumn{2}{|c|}{$r_{i}$} & \multicolumn{2}{|c|}{$q_{i}$} \\
\hline$N^{+}$ & & \multicolumn{2}{|c|}{0.2854} & \multicolumn{2}{|c|}{0.0920} \\
\hline \multirow[b]{2}{*}{$i$} & \multirow[b]{2}{*}{$j$} & \multicolumn{4}{|c|}{ Interaction Parameters } \\
\hline & & $a_{i j}$ & $a_{j i}$ & $b_{i j}$ & $C_{i j}$ \\
\hline $\mathrm{CH}_{2}$ & $N^{+}$ & 13274.342 & -3782.346 & - & - \\
\hline $\mathrm{CH}_{2}$ & $F^{-}$ & 542.4272 & 8589.996 & - & - \\
\hline $\mathrm{CH}_{2}$ & $\mathrm{Cl}^{-}$ & -2079.152 & -6336.760 & - & - \\
\hline $\mathrm{CH}_{2}$ & $\mathrm{Br}^{-}$ & -671.308 & -6435.327 & - & - \\
\hline $\mathrm{CH}_{2}$ & $I^{-}$ & 62650.253 & -6870.798 & - & - \\
\hline $\mathrm{H}_{2} \mathrm{O}$ & $N^{+}$ & 123.054 & 1698.363 & - & - \\
\hline$N^{+}$ & $F^{-}$ & 11619.598 & 5815.511 & 1.393 & -15.927 \\
\hline$N^{+}$ & $\mathrm{Cl}^{-}$ & 876.403 & 12505.214 & 1.138 & -3.692 \\
\hline$N^{+}$ & $\mathrm{Br}^{-}$ & 2701.832 & 641.027 & -0.517 & 12.739 \\
\hline$N^{+}$ & $I^{-}$ & -3906.310 & -9249.773 & -15.500 & 153.687 \\
\hline
\end{tabular}

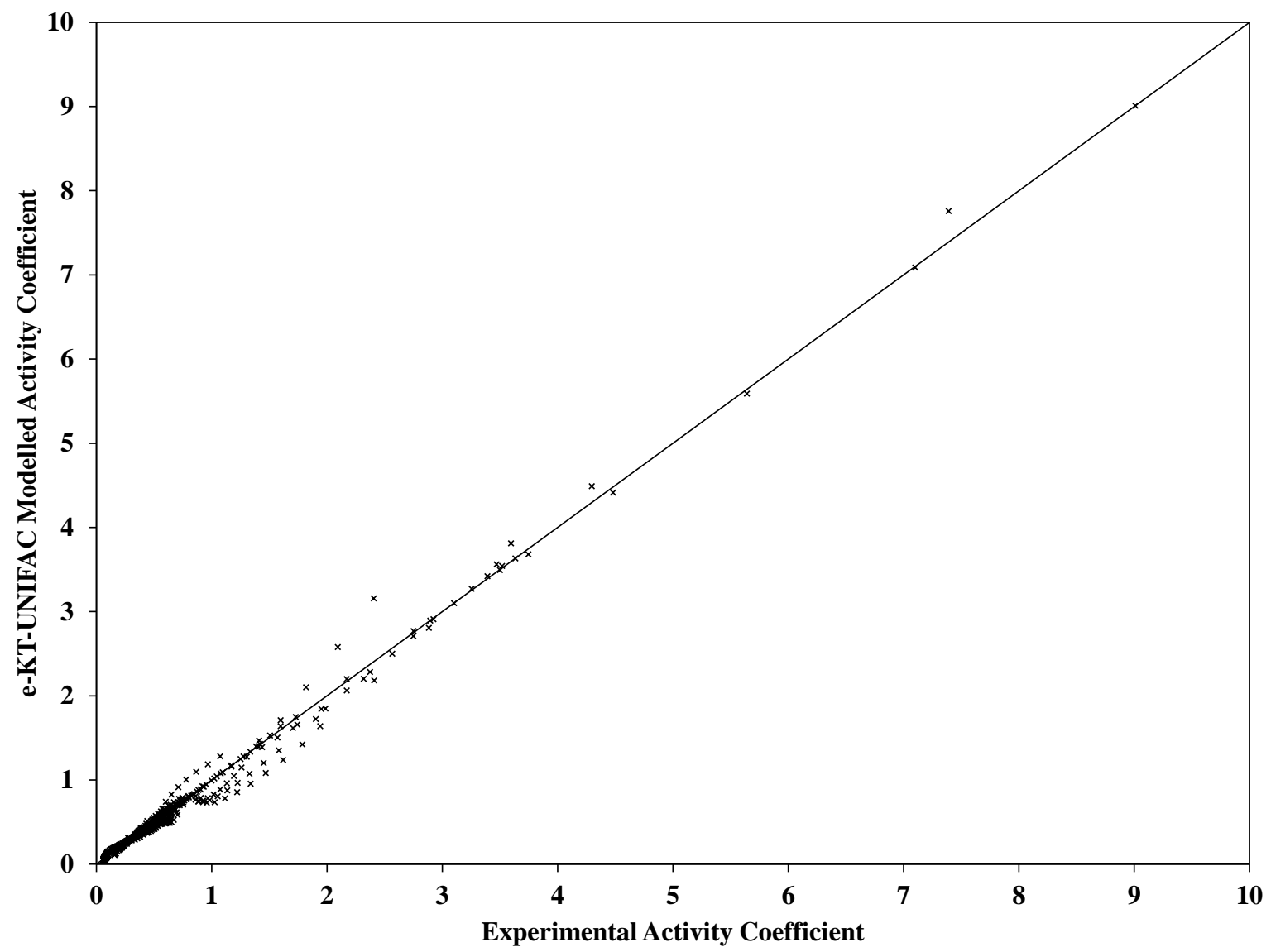

Figure 7: Comparison of e-KT-UNIFAC Model Calculations and Experimental Activity coefficients of Tetraalkylammonium PTC. 


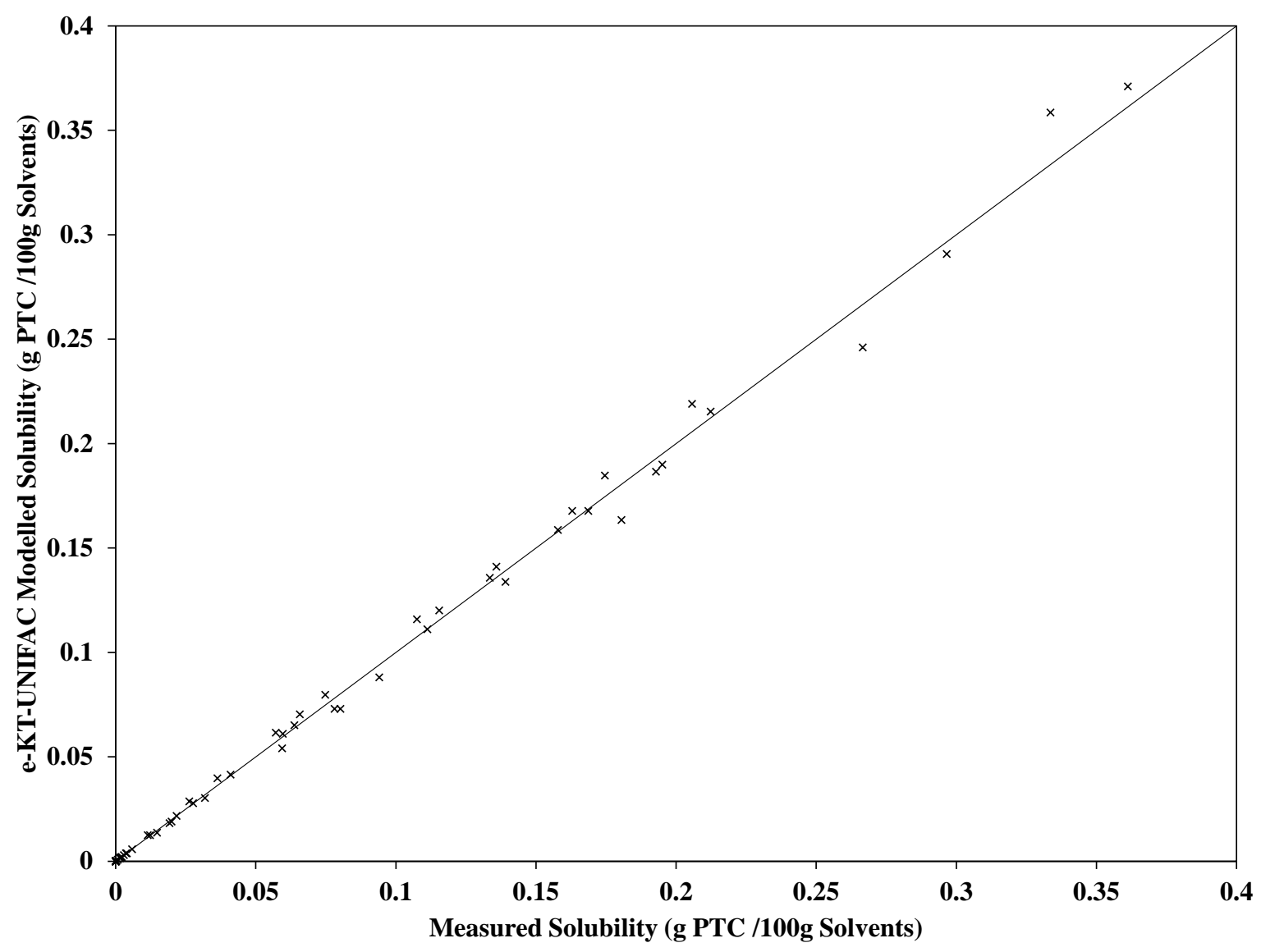

Figure 8: Comparison of e-KT-UNIFAC Model Calculations and Measured Solubilities of Tetraalkylammonium PTC.

\section{Modelling of Biphasic Reaction Systems with PTC}

This section presents some versions of PTC-based process models are constructed via the modelling framework given above. Process models are combined with thermodynamic models (see Section 2.2) to obtain the final system model capable of estimating the process design-performance variables (product yield, amount of impurities, acceleration of reactions, etc.). ICAS-MoT (Integrated Computer Aided System - Modelling Testbed) (Gani, 2003 \& 2015) has been used for the construction, analysis, and solving of the model. The parameter optimization/regression was solved using a successive quadratic programming (SQP) method incorporated in the software.

\subsection{Case Study: Benzoin Condensation Process}

Benzoin (2-hydroxy-1,2-diphenylethanone, $\mathrm{C}_{6} \mathrm{H}_{5} \mathrm{CH}(\mathrm{OH}) \mathrm{C}(\mathrm{O}) \mathrm{C}_{6} \mathrm{H}_{5}$ ) is a hydroxyl ketone used as a synthon for polymeric and pharmaceutical materials. Benzoin is produced by a condensation reaction of benzaldehyde $\left(\mathrm{C}_{6} \mathrm{H}_{5} \mathrm{CHO}\right)$ with a cyanide ion catalyst. In a PTC system, the benzaldehyde is principally in the organic phase with sodium cyanide in the aqueous phase. The PTC is tetrabutylammonium bromide (TBAB) (Yadav and Kadam, 2012) with the reaction mechanism shown in Figure 9. 


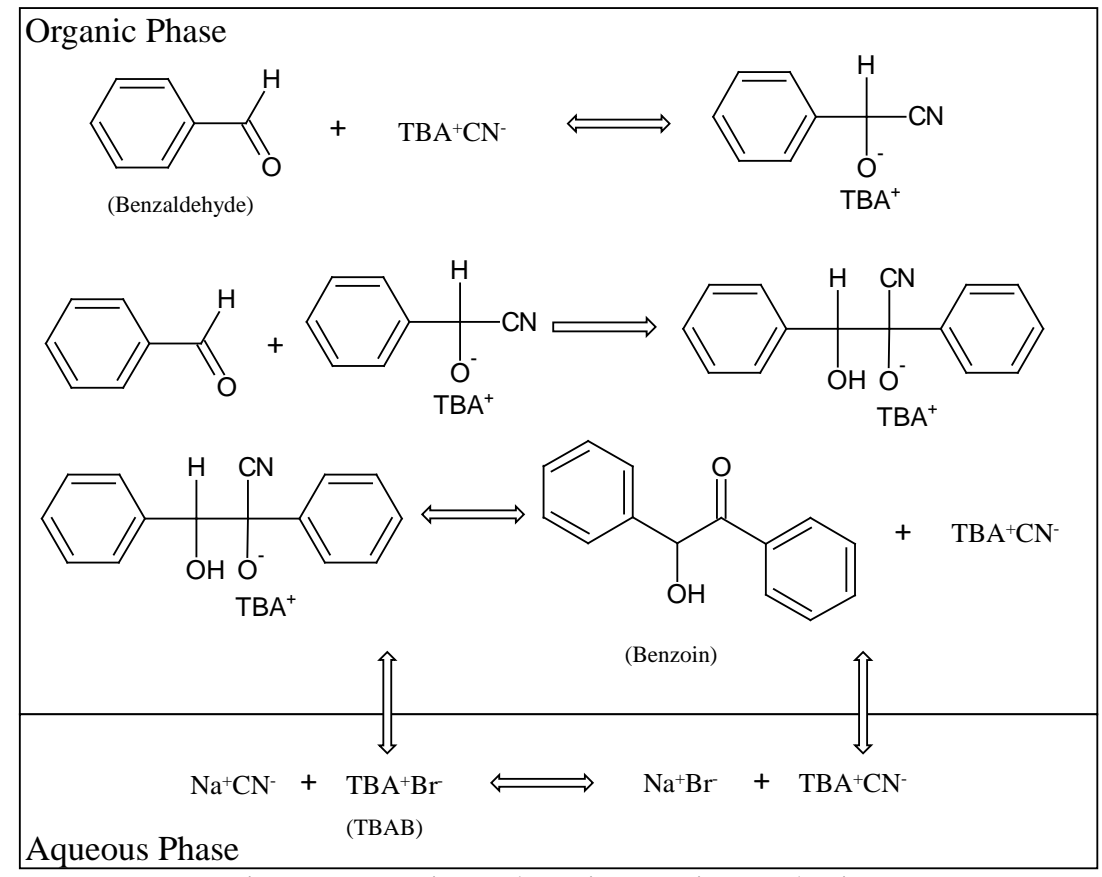

Figure 9: Benzoin condensation reaction mechanism

The reactor is of the batch type and the reactor operation starts in the aqueous phase with TBAB and sodium cyanide reacting to form tetrabutylammonium cyanide (TBACN, $\left.\mathrm{TBA}^{+} \mathrm{CN}^{-}\right)$and the spent salt sodium bromide. The TBACN is transferred from the aqueous phase to the organic phase to react with benzaldehyde, generating a carbanion intermediate compound. The carbanion undergoes a nucleophilic addition reaction with another benzaldehyde molecule. Then the cyanide group is eliminated, resulting in the benzoin product and a $\mathrm{TBA}^{+} \mathrm{CN}^{-}$ compound which transfers to the aqueous phase for another cycle. This system may be considered as pseudo phase transfer catalyst, since both the active and inactive PTC forms are not consumed during the reaction. Thus, the aqueous $\mathrm{Na}^{+} \mathrm{CN}^{-}$and PTC are treated as inert species at constant concentration.

In this case the model generation procedure has only TBAB and TBACN as heterogeneous species and water and toluene as solvents. Benzaldehyde and its intermediate compound, as well as both sodium salts are reactive species, and there is complete dissociation of sodium salts and tetrabutylammonium compounds in the aqueous phase.

For the reactions, the nucleophilic addition is considered as kinetically controlled, while the others are considered at equilibrium. It is also assumed that all reactions follow an elementary rate law, with no mass transfer limit, and the concentrations of TBAB and TBACN are assumed constant throughout the reaction period.

From Module 1, the distributions between aqueous $(\alpha)$ and organic $(\beta)$ phases of TBAB and TBACN are obtained as functions of activity coefficients, as given below.

$$
\begin{aligned}
& P_{T B A B}=\frac{\gamma_{T B A^{+}}^{\alpha} \gamma_{B r^{-}}^{\alpha}}{\gamma_{T B A B}^{\beta}} \\
& P_{T B A C N}=\frac{\gamma_{T B A^{+}}^{\alpha} \gamma_{C N^{-}}^{\alpha}}{\gamma_{T B A C N}^{\beta}} \\
& x_{T B A B}^{\beta}=P_{T B A B} x_{T B A^{+}}^{\alpha} x_{B r^{-}}^{\alpha} \\
& x_{T B A C N}^{\beta}=P_{T B A C N} x_{T B A^{+}}^{\alpha} x_{C N^{-}}^{\alpha}
\end{aligned}
$$


From Module 2, the reaction in the aqueous phase is considered at equilibrium.

$$
0=C_{N a C N}^{\alpha} \gamma_{N a C N}^{\alpha} C_{T B A B}^{\alpha} \gamma_{T B A B}^{\alpha}-\frac{C_{N a B r}^{\alpha} \gamma_{N a B r}^{\alpha} C_{T B A C N}^{\alpha} \gamma_{T B A C N}^{\alpha}}{K_{E q, 1}}
$$

In the organic phase, nucleophilic addition is a kinetically controlled reaction; while the other two reactions are at equilibrium.

$$
\begin{aligned}
& 0=C_{B} \gamma_{B} C_{T B A C N}^{\beta} \gamma_{T B A C N}^{\beta}-\frac{C_{C a b} \gamma_{C a b}}{K_{E q, 2}} \\
& R_{3}=k_{3} C_{B} C_{C a b} \\
& 0=C_{I} \gamma_{I}-\frac{C_{P} \gamma_{P} C_{T B A C N}^{\beta} \gamma_{T B A C N}^{\beta}}{K_{E q, 4}}
\end{aligned}
$$

where subscripts $B, C a b, I$, and $P$ denote benzaldehyde, carbanion, cyano-intermediate, and benzoin respectively.

For the balance module, the batch reactor model equation 5 does not have flow-in or flow-out terms. The reaction only changes the amounts of benzaldehyde and benzoin. Therefore, the balance equations are as given in equations 16 to 18, while the amounts of other species are implicitly calculated by the equilibrium equations 12 , 13 , and 15 .

$$
\begin{aligned}
& \frac{d \xi_{3}}{d t}=R_{3} V \\
& N_{B}=N_{B}^{0}-\xi_{3} \\
& N_{P}=N_{P}^{0}+\xi_{3}
\end{aligned}
$$

The NRTL and eNRTL models are combined with the above process model for the benzoin condensation process. Measured data are needed for regression of the kinetic parameter $k_{3}$. The interaction parameters were taken from Piccolo et al. (2012). The results of the full model calculations are given in section 4.1.

\subsection{Chlorination of Organobromine}

Organochloride is used as synthetic rubber in various chemical industries (Herriott and Picker, 1975; Kolvari et al., 2007), as an insecticide and intermediate in the agricultural industry (Naik and Doraiswamy, 1998; Kolvari et al., 2007), and as an intermediate for antibacterial production in the pharmaceutical industry (Jie et al., 2014). It can be synthesized by chlorination of organobromine with sodium chloride using tetraalkylammonium cation as a PTC.

Figure 10 shows the PTC reaction mechanism of organobromine chlorination. The process starts in the aqueous phase with the reaction between tetraalkylammonium bromide $\left(\mathrm{Q}^{+} \mathrm{Br}^{-}\right)$and sodium chloride. to generate the active PTC, tetraalkylammonium chloride $\left(\mathrm{Q}^{+} \mathrm{Cl}^{-}\right)$, that transfers from the aqueous to the organic phase. This active PTC reacts with organobromine to create organochloride and an inactive PTC that transfers back to aqueous phase for further reaction.

Here, there are 2 heterogeneous chemical species, tetraalkylammonium bromide and tetraalkylammonium chloride. Water and an organic compound are treated as solvents; in this case we have considered 13 immiscible organic substances to examine their differences in effectiveness (toluene, benzene, dichloromethane, methyl tertbutyl ether, dichloroethane, bromobenzene, chlorobenzene, chloroform, ethylacetate, methylcyclohexane, ethyl 
ether, cyclohexane, and hexane). The reactive species are organobromine, the PTC, and the sodium salts, and complete dissociation of sodium salts and tetrabutylammonium species is assumed in the aqueous phase.

Again, the process is a batch reactor without any mass transfer limit. The reaction in the organic phase has been formulated with both kinetic control and equilibrium control, depending on the design targets.

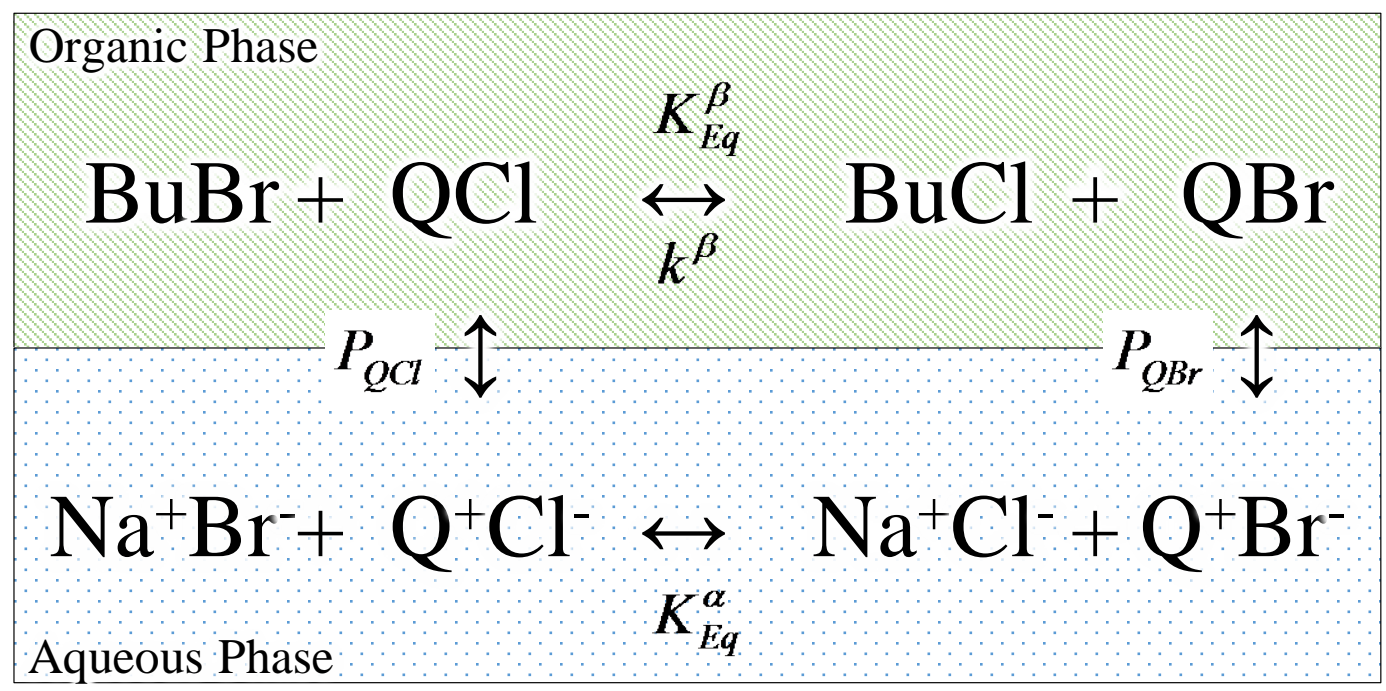

Figure 10: Chlorination of organobromine reaction mechanism

From Module 1, the distribution between aqueous ( $\alpha$ ) and organic ( $\beta$ ) phases of the active and inactive forms of the PTC (QBr and QCl) are obtained from activity coefficients.

$$
\begin{aligned}
& P_{Q B r}=\frac{\gamma_{Q^{+}}^{\alpha} \gamma_{B r^{-}}^{\alpha}}{\gamma_{Q B r}^{\beta}} \\
& P_{Q C l}=\frac{\gamma_{Q^{+}}^{\alpha} \gamma_{C l^{-}}^{\alpha}}{\gamma_{Q C l}^{\beta}} \\
& x_{Q B r}^{\beta}=P_{Q B r} x_{Q^{+}}^{\alpha} x_{B r}^{\alpha} \\
& x_{Q C l}^{\beta}=P_{Q C l} x_{Q^{+}}^{\alpha} x_{C l^{-}}^{\alpha}
\end{aligned}
$$

In Module 2, the aqueous phase reaction is in equilibrium.

$$
0=x_{X^{-}}^{\alpha} \gamma_{X^{-}}^{\alpha} x_{Q Y}^{\alpha} \gamma_{Q Y}^{\alpha}-K_{E q}^{\alpha} X_{Y^{-}}^{\alpha} \gamma_{Y^{-}}^{\alpha} x_{Q X}^{\alpha} \gamma_{Q X}^{\alpha}
$$

The reaction in the organic phase has been derived for PTC systems under three different operational scenario assumptions, depending on specified process design targets. The three cases are:

\subsubsection{Equilibrium model}

This model set is constructed to estimate the final amount of each species in both the aqueous and organic phases, with the assumption that the organic phase reaction is in equilibrium. One equation (24a) s used for the organic phase reaction with a known equilibrium constant, $K_{E q}^{\beta}$. 


$$
0=x_{R X} \gamma_{R X} x_{Q Y}^{\beta} \gamma_{Q Y}^{\beta}-K_{E q}^{\beta} x_{R Y} \gamma_{R Y} x_{Q X}^{\beta} \gamma_{Q X}^{\beta}
$$

\subsubsection{Conversion model}

This model is used when the extent of conversion of the limiting reactant is specified. It is used to estimate the amounts of each species in both phases at a given conversion. The conversion model uses one equation (25b) along with one parameter, the conversion $C^{\beta}$.

$$
\xi^{\beta}=C^{\beta} N_{R B r}^{0}
$$

\subsubsection{Kinetic model}

This model is a time-dependent model for estimating the apparent rate of reaction. The model is used for designing a reaction system with the intention of improving the overall production rate. It requires 2 equations (25c and 25d) and one parameter, the rate of organic phase reaction $k_{\beta}$.

$$
\begin{aligned}
& \frac{d \xi^{\beta}}{d t}=R^{\beta} V \\
& R^{\beta}=k_{\beta} C_{R B r} C_{Q C l}^{\beta}
\end{aligned}
$$

From Module 3, the batch reactor model (no inlet and outlet flows) is used. The changes in reactive species depend on whether an equilibrium, conversion, or kinetic model. This gives 8 balance equations (25 to 32) for each species type.

$$
\begin{aligned}
& N_{B r^{-}}^{\alpha}=N_{B r^{-}}^{0}+\xi^{\alpha} \\
& N_{C l^{-}}^{\alpha}=N_{C l^{-}}^{0}-\xi^{\alpha} \\
& N_{R X}^{\beta}=N_{R X}^{0}-\xi^{\beta} \\
& N_{R Y}^{\beta}=N_{R Y}^{0}+\xi^{\beta} \\
& N_{Q C l}^{\beta}=N_{Q C l}^{T}-N_{Q C l}^{\alpha} \\
& N_{Q B r}^{\beta}=N_{Q B r}^{T}-N_{Q B r}^{\alpha} \\
& N_{Q B r}^{T}=N_{Q B r}^{\alpha, 0}+N_{Q B r}^{\beta, 0}-\xi^{\alpha}+\xi^{\beta} \\
& N_{Q C l}^{T}=N_{Q C l}^{\alpha, 0}+N_{Q C l}^{\beta, 0}+\xi^{\alpha}-\xi^{\beta}
\end{aligned}
$$

The equilibrium model requires no regressed parameters, while each of the conversion and kinetic models require one parameter, $C^{\beta}$ for the conversion model, and $k_{\beta}$ for kinetic model. Section 4.2 gives the results using the SAC thermodynamic models, while in Section 4.3 are given results for the equilibrium model using the e-KTUNIFAC for estimating activity coefficients.

\section{Model-Based Design and Analysis of the Systems}

In this section, the applications of the constructed models are described in detail. In section 4.1 the benzoin condensation model from section 3.1 is combined with the eNRTL models to follow the benzoin condensation process with various initial conditions. Then, combinations of three reacting models from section 3.2, combined with thee-NRTL-SAC and the e-KT-UNIFAC models are presented in sections 4.2 and 4.3, respectively. The 
SAC correlation is used to highlight designs with the most efficient solvents for different process design targets, while the e-KT-UNIFAC combination is used to highlight predictive possibilities related to design of the more effective and novel PTC cations.

\subsection{Benzoin Condensation}

In this case study, a pseudo-PTC reacting model (equations 9 to 19) is combined with NRTL/eNRTL the thermodynamic models for the prediction of benzoin condensation process behaviour. The objective is to check the applicability of the NRTL and eNRTL models.

For the benzoin condensation process case study, there are 12 sets of measured data with various initial conditions collected from literature (Yadav and Kadam, 2012). One of the sets is selected for the parameter regression for the rate of reaction $\left(k_{3}\right)$ from equation 15 . The regressed value is $1.28 \times 10^{4} \mathrm{~cm}^{3} / \mathrm{s} \cdot \mathrm{mol}$, figure 11 shows an acceptable fitting between the measured conversion of benzaldehyde and calculated value from the model.

The regressed parameter is used to determine the effect of the initial amounts of benzaldehyde, salt, and PTC needed for the known rate of reaction. As shown in figure 12 over wide ranges of initial amounts of PTC, salt and reactant, the deviations of estimated conversion of benzaldehyde are less than $10 \%$ from measured data. The data used and calculated values of figure 12 are given as supplementary material to this paper (see Table S-I).

Thus, the combination of NRTL and eNRTL, can be used to predict the PTC system behaviour with regression of a minimum of available experimental data for the specific rate of each reaction.

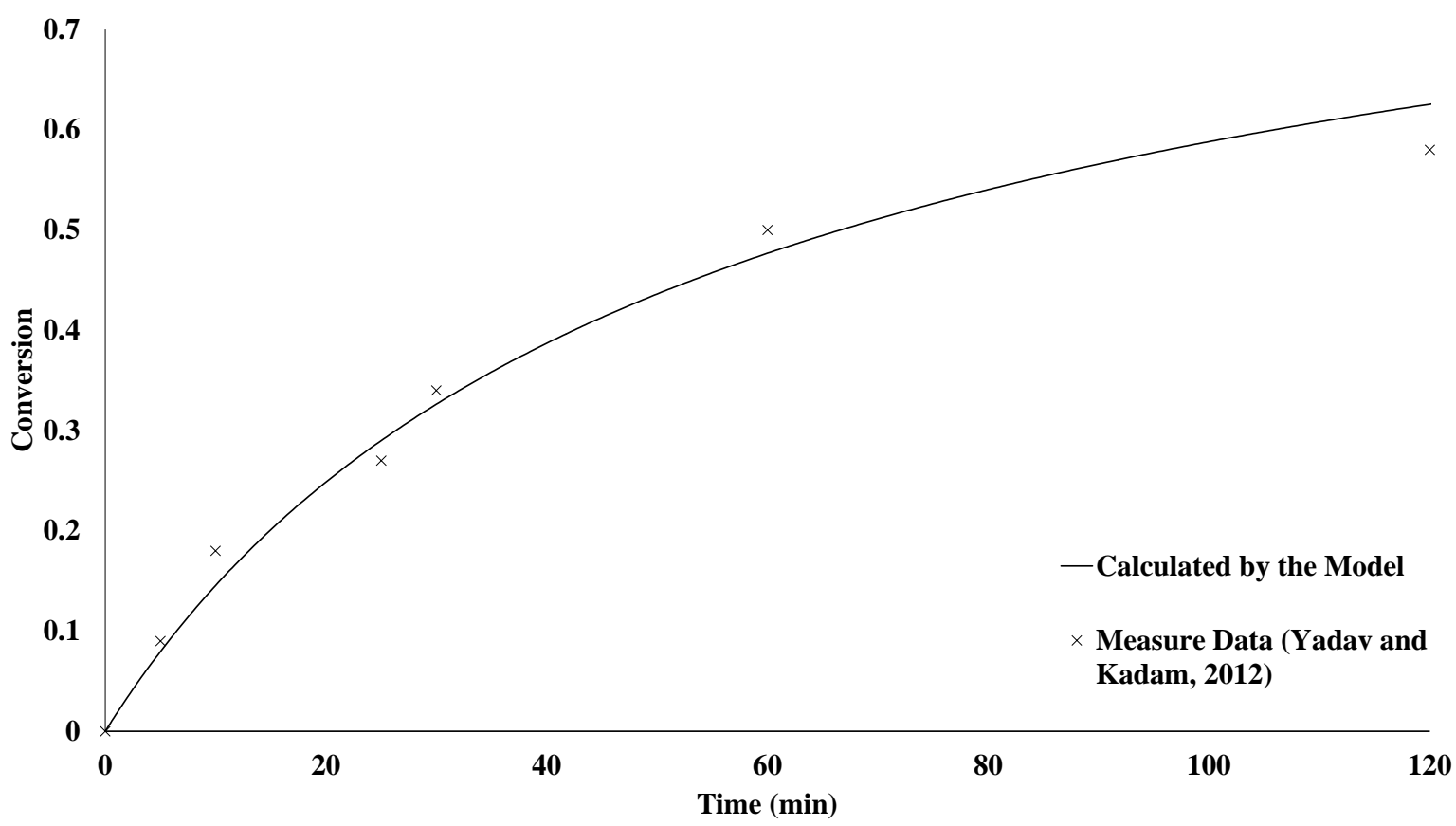

Figure 11: Conversion of benzaldehyde to benzoin over time with comparisons between measured data and model calculations 


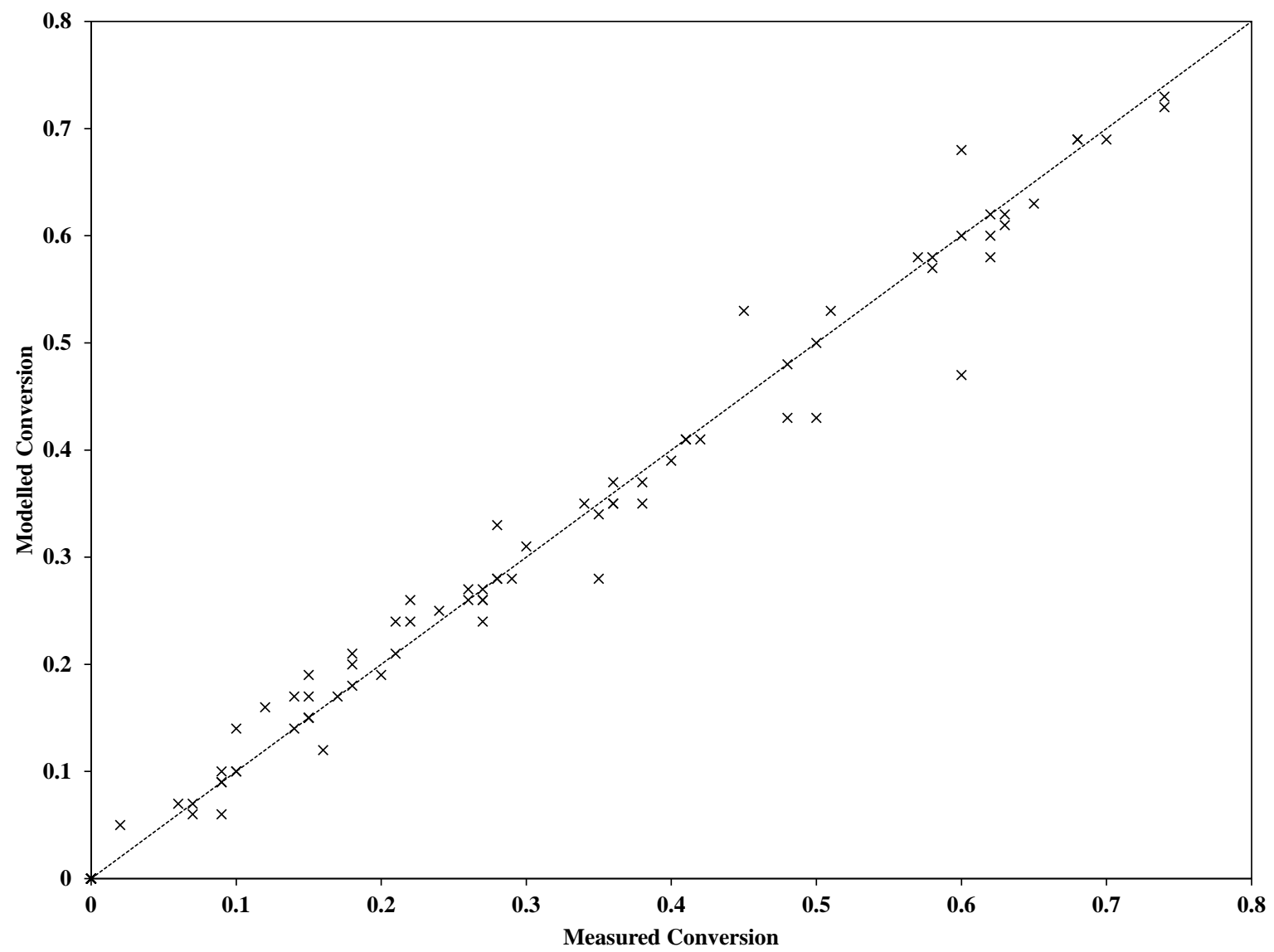

Figure 12: Conversion rates of benzaldehyde to benzoin at various initial conditions comparing model prediction and measured data

\subsection{Chlorination of Organobromine - I}

The chlorination of butyl bromide $\left(\mathrm{C}_{4} \mathrm{H}_{9} \mathrm{Br}\right)$ to butyl chloride $\left(\mathrm{C}_{4} \mathrm{H}_{9} \mathrm{Cl}\right)$ is first used to check the applicability of the SAC model. Different equation sets from section 2 and 3 are combined with the SAC model and employed for the design of reacting systems with different specified process design targets.

All calculations use the same initial feed, operating conditions, and reactor volume, as given in Table 5.

Table 5: Initial conditions of organobromine chlorination

\begin{tabular}{lc}
\hline & Value \\
\hline Temperature (K) & 298.15 \\
\hline Initial mass of reactive species $\left(m_{i}^{0}-\mathbf{k g}\right)$ & \\
$\mathrm{C}_{4} \mathrm{H}_{9} \mathrm{Br}$ & 50 \\
\hline $\mathrm{NaCl}$ & 100 \\
\hline $\mathrm{NaBr}$ & 0 \\
\hline $\mathrm{QBr}$ & 2 \\
\hline $\mathrm{QCl}$ & 0 \\
\hline Initial mass of products, $\mathrm{C}_{4} \mathrm{H}_{9} \mathrm{Cl}$ & 0 \\
\hline Solvents (Volume, dm $\left.{ }^{3}\right)$ & 1000 \\
\hline$\quad \quad$ Water & 1000 \\
\hline$\quad \quad$ Solvent
\end{tabular}




\subsubsection{Maximizing Product Yield as Design Target}

To maximize the amount of the product $\left(\mathrm{C}_{4} \mathrm{H}_{9} \mathrm{Cl}\right)$ as the specified design target, the equilibrium equations 20 to 24, 25a, and 26 to 33) are used to estimate the maximum amount of the product in the reacting system.

Reactive systems with tetrabutylammonium, $\left(\mathrm{C}_{4} \mathrm{H}_{9}\right)_{4} \mathrm{~N}^{+}$, as PTC with 6 different solvents are studied. The results of calculations are shown in figure 13. Among the 6 solvents studied, Reactions with hexane, chloroform, and toluene as organic solvents give similar conversions of around $70 \%$ ( with toluene an chloroform highest at $73 \%$ ), while reaction with benzene and ethyl acetate yield less than $40 \%$ conversion and cyclohexane yields only $27 \%$. These differences are enough to suggest careful solvent selection. Note that chloroform might involve a side effect in the reaction mechanism because its structure is close to that of the product.

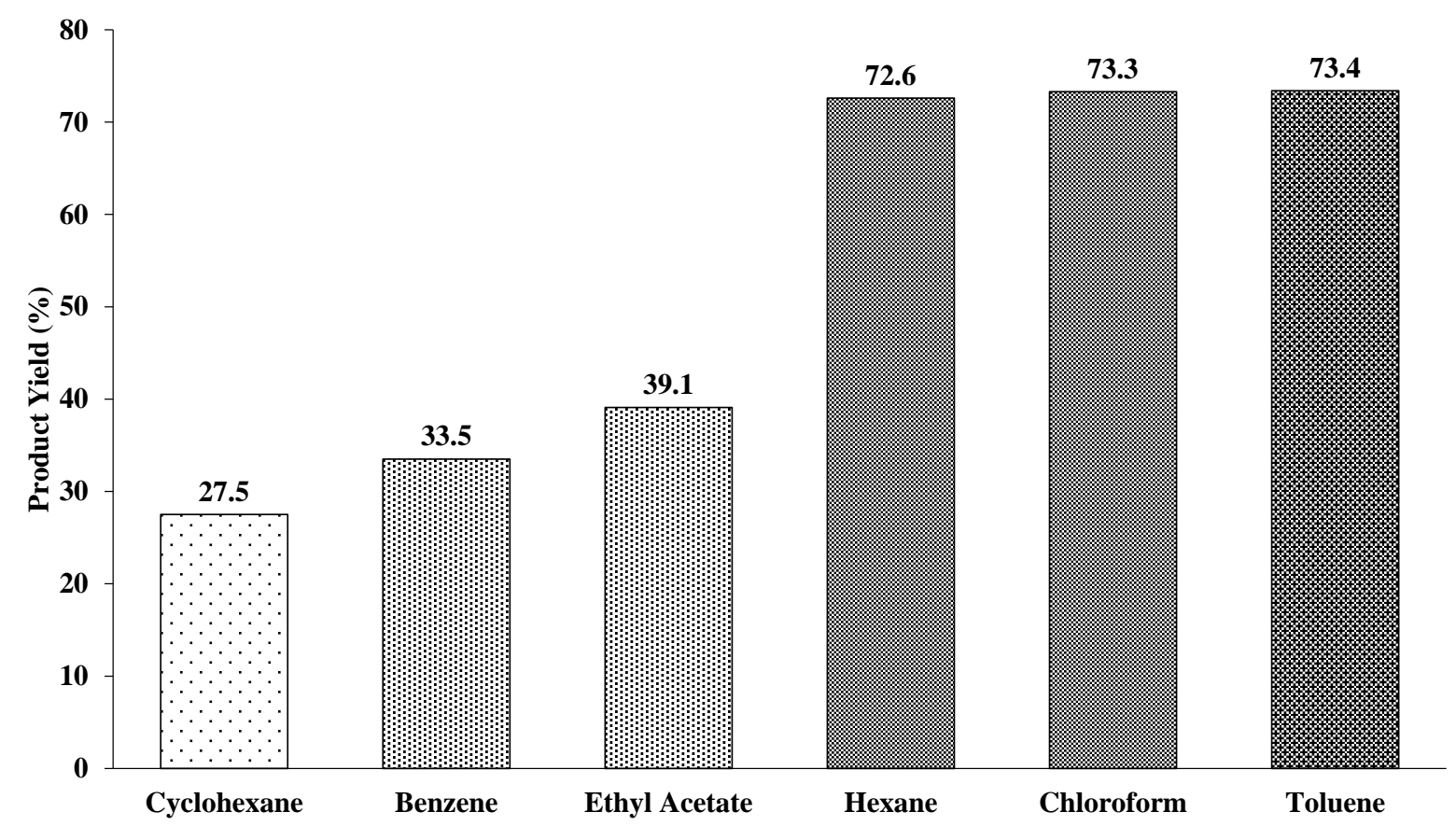

Figure 13: Maximum possible product yields of Butyl Bromide with in different solvents tetrabutylammonium PTC

\subsubsection{Minimizing Organic Phase Impurities}

The amount of impurities that remain in the organic phase with the main product varies with the type of solvents and PTCs used. The objective of this example is to show the minimum of impurity species that remains with the product at different stages of the reaction and with different substituents. The conversion equations 20 to 24, 25b, and 26 to 33 are used. Based on the results shown above section where hexane and toluene yielded high conversions, we selected these solvents and also the PTCs, tetraethylammonium, $\left(\mathrm{C}_{2} \mathrm{H}_{5}\right)_{4} \mathrm{~N}^{+}$and tetrabutylammonium, $\left(\mathrm{C}_{4} \mathrm{H}_{9}\right)_{4} \mathrm{~N}^{+}$for study.

Figure 14 shows the impurity levels for the four combinations of solvents and PTC at different amounts of conversion. Overall, reactions with tetraethylammonium PTC, in both toluene and hexane, give smaller impurities than reactions with tetrabutylammonium PTC at essentially all conversion level. Moreover, as the reaction progresses, the amounts of impurities decrease for them. While initially impurities in toluene are higher than in hexane it becomes lowest at a conversion of 0.7. Interestingly, with tetrabutylammonium PTC in toluene, the amount of impurities at low conversion is nearly the same as with tetraethylammonium, but as the reaction progresses, the impurities increase, not decrease.

The different partition coefficients $\left(P_{i}=\frac{\gamma_{i}^{\alpha}}{\gamma_{i}^{\beta}}\right)$ of the active (chloride) and inactive (bromide) forms of tetraethyland tetrabutylammonium PTC (see also table S-II, supplementary material for more detail) is the main reason for the observed behaviours. The partition coefficients of tetraethylammonium bromide $\left(P_{Q B r}\right)$ in both hexane and 
toluene are lower than the partitioning of tetraethylammonium chloride $\left(P_{\mathrm{QCl}}\right)$. At low conversion, there is a high concentration of the chloride species, leading to the formation of active PTC, which in turn, partitions well into the organic phase. As the reaction progresses, the active species becomes spent, and the PTC stays in the inactive form, which is not well partitioned into the organic phase. On the other hand, the partition coefficients of tetrabutylammonium PTC are opposite; the partitioning into the organic phase of inactive butyl PTC is higher than that of the active species. Then, as the reaction progresses, the inactive PTC accumulates in the organic phase, decreasing the reaction extent.

The result is that minimum impurities occur when tetraethylammonium PTC is used with toluene or hexane as solvents.

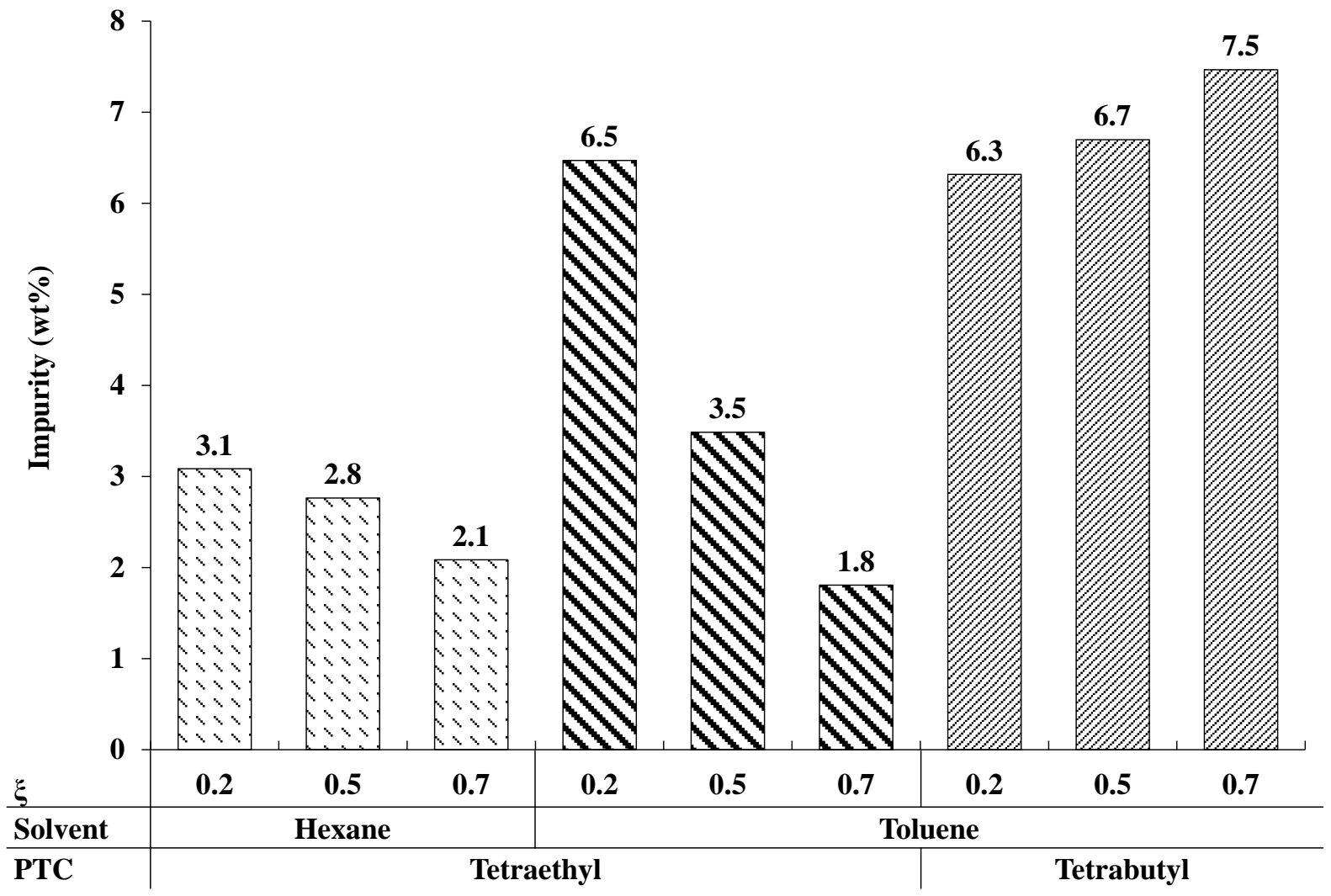

Figure 14: Impurity amounts in the organic phase at different conversions with different PTCs and solvents

\subsubsection{Accelerating the Reaction}

The speed of the reaction is a key design issue in reactive systems. In general, the kinetic model equations 20 to $24,25 c-d$, and 26 to 33 are used to estimate the system half-life, equilibrium time, and apparent rate of reaction. The apparent reaction rate $\left(k_{A p p}\right)$ is influenced by the kinetic parameters and the concentrations of the reactant and PTC. For a given reaction at fixed concentrations, when the activity coefficient of an active PTC in the organic phase $\left(\gamma_{\mathrm{QCl}}^{\beta}\right)$ increase -lowering the PTC partitioning - the system half-life and time to equilibrium increase and the apparent reaction rate decreases.

For the examples above under the same initial conditions (see Table 5), results for 42 systems with pairs formed by 14 solvents and 3 PTCs have been calculated. The detailed results of these calculations are given in supplementary material (see Table S-II). For the chlorination reaction, Figure 15 shows the half-life and time to equilibrium, while Figure 16 shows the apparent reaction rate. Since the equilibrium time is always around two orders of magnitude higher than the half-life, it takes almost two hours for the reaction to move from halfconversion to equilibrium. 
The simulated results show that the fastest time to equilibrium is for dichloromethane as a solvent with tetramethylammonium $\left(\left(\mathrm{CH}_{3}\right)_{4} \mathrm{~N}^{+}\right)$as the PTC. The slowest reaction, around eight orders of magnitude slower, is with hexane solvent and the same tetramethylammonium as PTC. Thus, only changing the solvent seems to vary the rate of reaction by orders of magnitude. Of course, experimental verification of this effect will be necessary to validate this significant result.

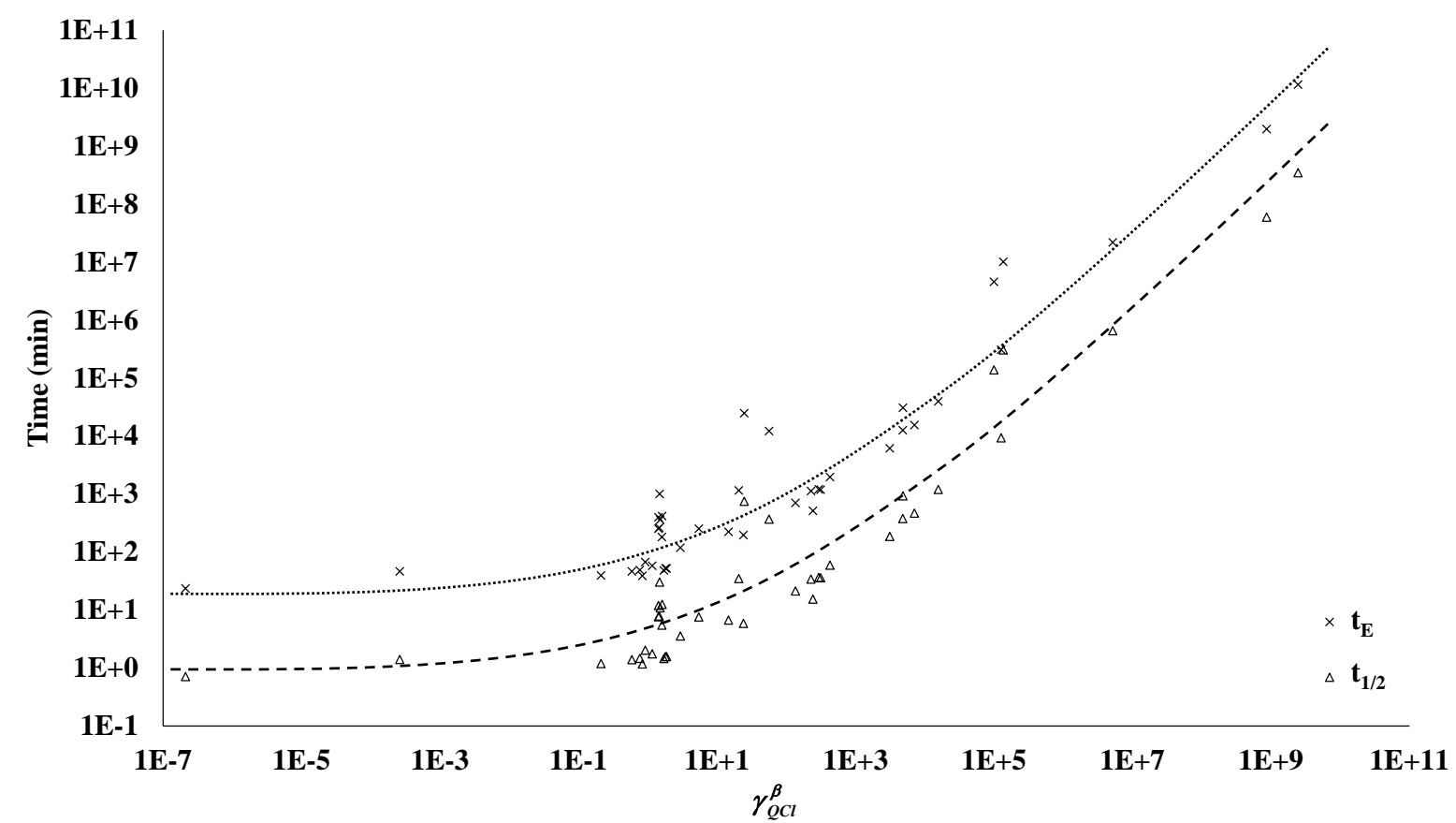

Figure 15: Relation between activity coefficient of active PTC organic phase $\left(\gamma_{\mathrm{QCl}}^{\beta}\right)$ and the reaction half-life $\left(t_{1 / 2}\right)$ and equilibrium time $\left(t_{E}\right)$ calculated from the kinetic model

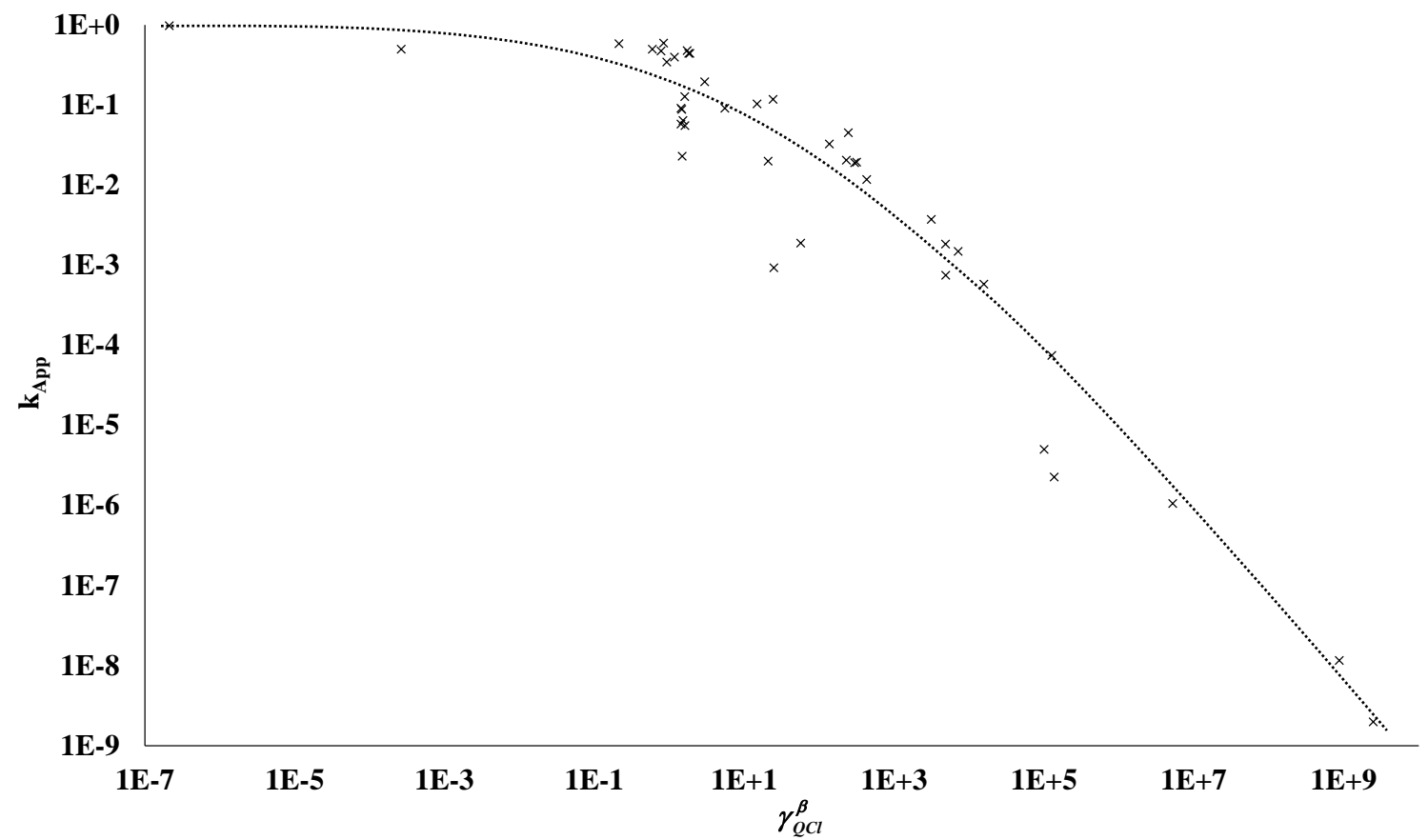

Figure 16: Relation between activity coefficient of active PTC organic phase $\left(\gamma_{\mathrm{QCl}}^{\beta}\right)$ and the apparent reaction rate $\left(k_{A p p}\right)$ 


\subsubsection{Optimizing the PTC Feed Amount}

In order to avoid loss or overuse of the valuable tetraalkylammonium PTC, optimization of the fed amount of PTC should be considered as a design target. We use the kinetic model equations to select the optimal feed amount of PTC with varied concentration of the fed PTC in the inactive form. For the chlorination of organobromine this is $\mathrm{Q}^{+} \mathrm{Br}^{-}$. The PTC is in four species forms as shown in Figure 10: (1) active species in the aqueous phase $(Q C l)^{\alpha}$ , (2) active species in the organic phase $(Q C l)^{\beta}$, (3) inactive species in the aqueous phase $(Q B r)^{\alpha}$, and (4) inactive species in the organic phases $(Q C l)^{\beta}$. The mole fractions of the PTC species are shown in Figure 17 as a function of the fed PTC concentration. In the chlorination of organobromine system, it is preferable to have the active form of tetraalkylammonium chloride $(\mathrm{QCl})$ in the organic phase.

Below the optimum feed region (less than nine molar initial PTC), the PTC converted to active species (QCl), but it stays mainly in the aqueous phase so the organic phase reaction is slow. In the optimum PTC feed region (between 9 and 32 molar initial PTC), the PTC is transferred to the organic phase accelerating the reaction. However, above the optimum region, the PTC accumulates as inactive species in the organic phase shifting the reaction backwards, slowing the rate of product formation, and wasting catalyst.

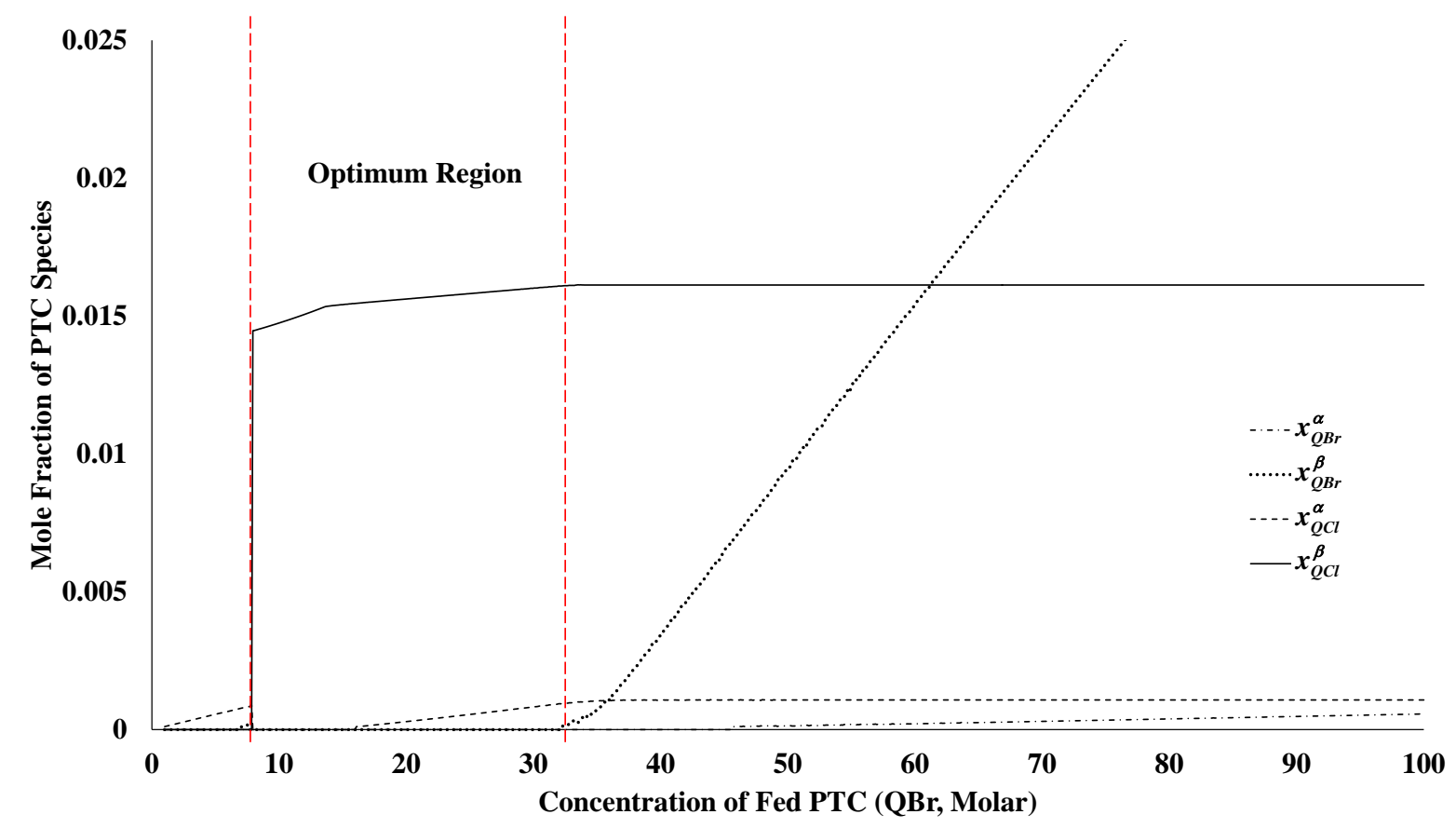

Figure 17: Relationship between amounts of PTC fed and the distribution of its into each form in both phases calculated by the kinetic model

\subsection{Chlorination of Organobromine - II}

The combination of the SAC thermodynamic model with different reactor models was shown in section 4.2. However, these estimations required measured data and cannot be reliable in predictions. The newly developed e-KT-UNFAC, which is based on group contributions can be used good for synthesis-design objectives for both the aqueous and organic phases without data.

In the present work, a new PTC-related group, $N^{+}$, has been defined, structural parameters $(r$ and $q$ ) calculated, and its interaction parameters for existing KT-UNIFAC groups, ion groups, and itself have been regressed from the experimental data of PTCs containing four to sixteen carbon atoms. Group configurations of the 98 distinct PTC cations so created are given in supplementary material (Table S-III).

The predictive capability of the e-KT-UNIFAC model is demonstrated with the design target to maximize the product yield for the chlorination of organobromine process for the 6 solvents of Section 4.2.1. In total, 588 pairs of solvent-PTC reactive systems have been considered for this case. 
The detailed results of the calculated conversions of the raw material in the different reacting systems are given in supplementary material (Table S-IV). The calculated conversions range from $21 \%$ to $99 \%$. The maximum, minimum and average conversions obtained with different chain lengths of the PTC are shown in Figure 18, the average conversions increase with the number of attached carbon atoms from 4 to 12 atoms and then decrease from 12 to 16 atoms. The maximum, minimum and average conversions for different solvents are shown in Figure 19, with hexane given highest average conversion as well as the highest possible conversion.

The highest conversion of $98.9 \%$ is achieved with hexane as the solvent and a 12 carbon atom PTC. The PTC cation groups are ammonium $\left(\mathrm{N}^{+}\right), 6 \mathrm{CH}_{3}, 5 \mathrm{CH}_{2}$, and $1 \mathrm{C}$. The lowest conversion of $20.9 \%$ appears with cyclohexane as the solvent and a 16 carbon atom PTC.

The calculated conversions with the e-KT-UNIFAC and SAC model (of Section 4.2.1) are very similar, suggesting that for this case, the models are equivalent (Table 6).

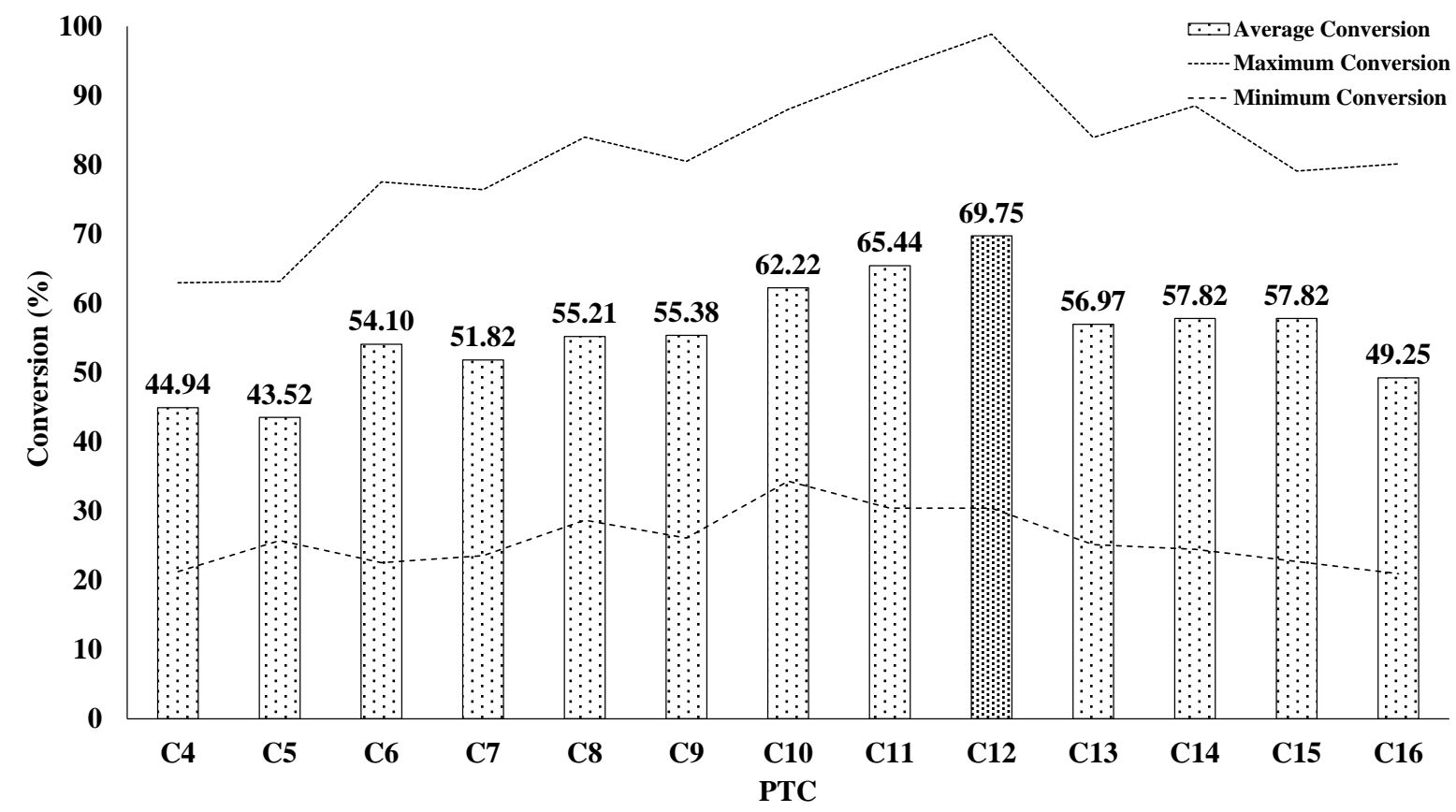

Figure 18: Maximum, minimum, and average conversion achieved for the chlorination of organobromine by different tetraakylammonium PTCs 


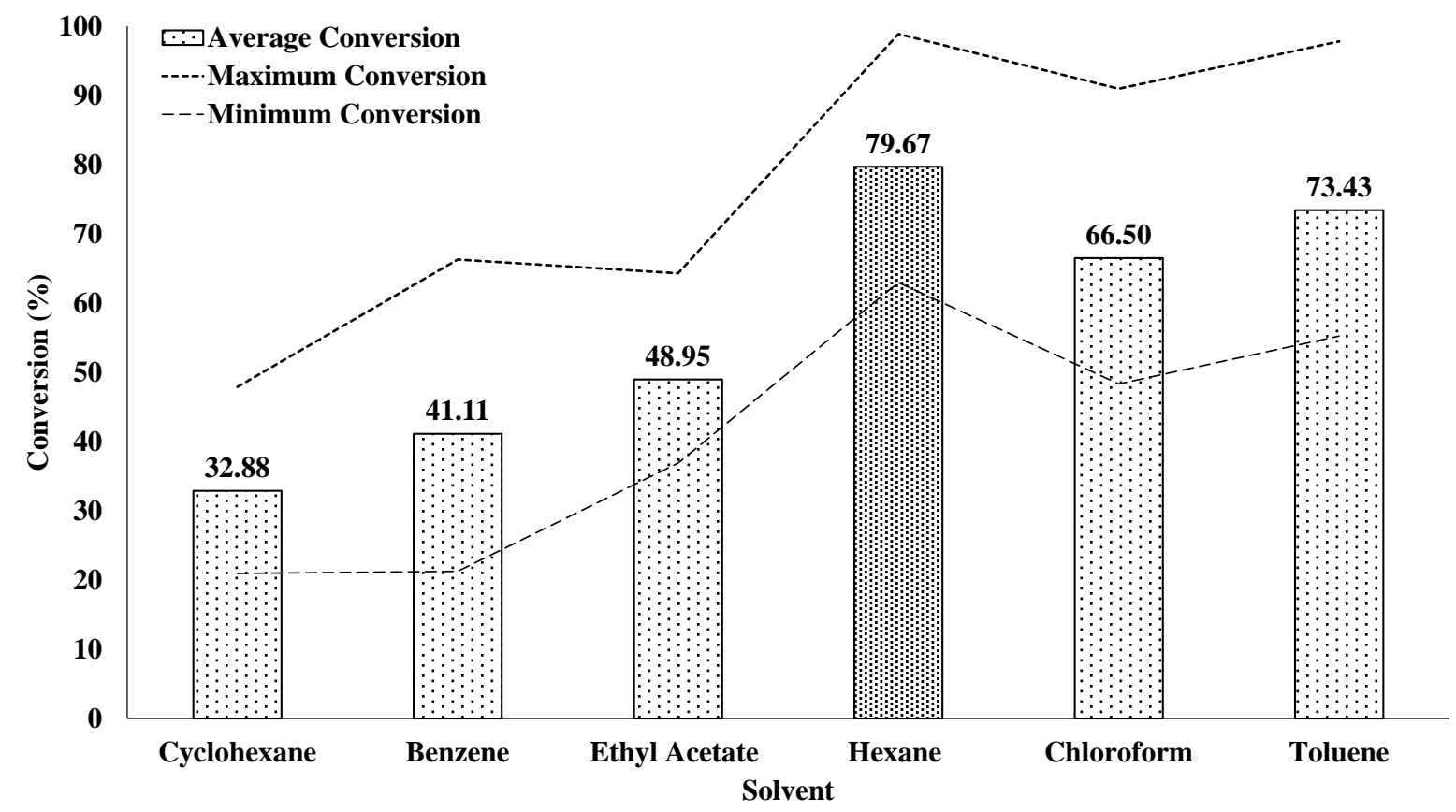

Figure 19: Maximum, minimum, and average conversion for the chlorination of organobromine with the tetraalkylammonium PTC and different solvents

Table 6: Comparison of conversions calculated with the SAC and e-KT-UNIFAC models

\begin{tabular}{lcc}
\hline \multirow{2}{*}{ Solvent } & \multicolumn{2}{c}{ Conversion calculated by } \\
\cline { 2 - 3 } & SAC models & e-KT-UNIFAC model \\
\hline Cyclohexane & 27.52 & 27.51 \\
Eenzene & 33.47 & 32.23 \\
Ethyl Acetate & 39.10 & 40.66 \\
\hline Chexane & 72.65 & 71.85 \\
\hline Toluene & 73.33 & 71.41 \\
\hline
\end{tabular}

\section{Conclusions}

A modelling framework for biphasic Phase Transfer Catalysis (PTC) reacting systems has been implemented with both correlative and predictive constitutive thermodynamic models. The framework allows the construction of problem-specific models for different reaction conditions, PTCs, and solvents.

Case studies of benzoin condensation and chlorination of organobromines have been successfully analysed with the modelling framework. A pseudo-PTC model together with NRTL/eNRTL constitutive thermodynamic models accurately estimates rates and yields for the benzoin condensation under different initial conditions.

Three sets (equilibrium, conversion, and kinetic) of models for the chlorination process have been constructed and evaluated for different combinations of solvents and PTC using the SAC and e-KT-UNIFAC constitutive models. Certain combinations of PTC and solvent show maximal conversion and rate, these results suggest that the current version of the framework has promise for a wide range of PTC reacting systems.

\section{Acknowledgements}

The authors would like to thanks Prof. Héctor Felipe López Isunza of Universidad Autónoma Metropolitana, Mexico for the helpful discussions during the period of this work. 


\section{References}

Abraham, M., 1970. Solvent effects on the free energies of ion-pairs, and of transition states in an SN1 and an SN2 reaction. Tetrahedron Lett. 11, 5233-5236. doi:10.1016/S0040-4039(00)99982-9

Abraham, M.H., 1973. Ionic entropies of transfer from water to nonaqueous solvents. J. Chem. Soc. Faraday Trans. 1 69, 1375. doi:10.1039/f19736901375

Abraham, M.H., 1972. Substitution at saturated carbon. Part XIV. Solvent effects on the free energies of ions, ion-pairs, nonelectrolytes, and transition states in some S N and S E reactions. J. Chem. Soc. Perkin Trans. 21343. doi:10.1039/p29720001343

Abraham, M.H., 1971. Substitution at saturated carbon. Part VIII. Solvent effects on the free energy of trimethylamine, the nitrobenzyl chlorides, and the trimethylamine-nitrobenzyl chloride transition states. J. Chem. Soc. B Phys. Org. 299. doi:10.1039/j29710000299

Acree Jr., W.E., Abraham, M.H., Acree, Jr., W.E., Abraham, M.H., 2001. Solubility predictions for crystalline nonelectrolyte solutes dissolved in organic solvents based upon the Abraham general solvation model. Can. J. Chem. 79, 1466-1476. doi:10.1139/v01-165

Amado, E., Blanco, L.H., 2009. Isopiestic Determination of the Osmotic and Activity Coefficients of Aqueous Solutions of Symmetrical and Unsymmetrical Quaternary Ammonium Bromides at T = (283.15 and 288.15) K †. J. Chem. Eng. Data 54, 2696-2700. doi:10.1021/je900216m

Anantpinijwatna, A., Sin, G., O’Connell, J.P., Gani, R., 2014. A Framework for the Modelling of Biphasic Reacting Systems. Comput. Aided Chem. Eng. 34, 249-254. doi:10.1016/B978-0-444-63433-7.50026-2

Belvèze, L.S., Brennecke, J.F., Stadtherr, M.A., 2004. Modeling of Activity Coefficients of Aqueous Solutions of Quaternary Ammonium Salts with the Electrolyte-NRTL Equation. Ind. Eng. Chem. Res. 43, 815-825. doi:10.1021/ie0340701

Blanco, L.H., Eliseo Amado, G., Calvo, J.C., 2008. Osmotic and activity coefficients of dilute aqueous solutions of the series Me4NI to MeBu3NI at 298.15K. Fluid Phase Equilib. 268, 90-94. doi:10.1016/j.fluid.2008.04.008

Boyd, G.E., Schwarz, A., Lindenbaum, S., 1966. Structural Effects on the Osmotic and Activity Coefficients of the Quaternary Ammonium Halides in Aqueous Solutions at 25² 1. J. Phys. Chem. 70, 821-825. doi:10.1021/j100875a034

Cameron, I.T., Gani, R., 2011. Product and Process Modelling A Case Study Approach. Elsevier Science, Amsterdam.

Chandler, K., Culp, C.W., Lamb, D.R., Liotta, C.L., Eckert, C.A., 1998. Phase-Transfer Catalysis in Supercritical Carbon Dioxide: Kinetic and Mechanistic Investigations of Cyanide Displacement on Benzyl Chloride. Ind. Eng. Chem. Res. 37, 3252-3259. doi:10.1021/ie970741h

Chen, C.-C., Song, Y., 2005. Extension of Nonrandom Two-Liquid Segment Activity Coefficient Model for Electrolytes. Ind. Eng. Chem. Res. 44, 8909-8921. doi:10.1021/ie0503592

Chen, C.-C., Song, Y., 2004. Solubility modeling with a nonrandom two-liquid segment activity coefficient model. Ind. Eng. Chem. Res. 43, 8354-8362. doi:10.1021/ie049463u

Constantinou, L., Gani, R., 1994. New group contribution method for estimating properties of pure compounds. AIChE J. 40, 1697-1710. doi:10.1002/aic.690401011

de Zani, D., Colombo, M., 2012. Phase-Transfer Catalysis under Continuous Flow Conditions: An Alternative Approach to the Biphasic Liquid/Liquid O-Alkylation of Phenols. J. Flow Chem. 5-7. doi:10.1556/jfchem.2012.00020

Dehmlow, E. V., 1974. Phase-Transfer Catalyzed Two-Phase Reactions in Preparative Organic Chemistry. Angew. Chemie Int. Ed. English 13, 170-179. doi:10.1002/anie.197401701

Eliseo, A.G., Blanco, L.H., 2006. Osmotic and activity coefficients of dilute aqueous solutions of symmetrical and unsymmetrical quaternary ammonium bromides at 293.15K. Fluid Phase Equilib. 243, 166-170. doi:10.1016/j.fluid.2006.03.001

Franks, F., Clarke, D.L., 1967. Solubilities of alkylammonium iodides in water and aqueous urea. J. Phys. Chem. 71, 11551156. doi:10.1021/j100863a065

G, E.A., Blanco, L.H., 2005. Isopiestic determination of the osmotic and activity coefficients of dilute aqueous solutions of symmetrical and unsymmetrical quaternary ammonium bromides with a new isopiestic cell at $298.15 \mathrm{~K}$. Fluid Phase Equilib. 233, 230-233. doi:10.1016/j.fluid.2005.04.012

Gani, R., 2015. ICAS Documentations. Intern. Report, Tech. Univ. Denmark.

Herriott, A.W., Picker, D., 1975. Phase transfer catalysis. Evaluation of catalysis. J. Am. Chem. Soc. 97, $2345-2349$. doi:10.1021/ja00842a006

Jaime-Leal, J.E., Bonilla-Petriciolet, A., Bhargava, V., Fateen, S.E.K., 2014. Nonlinear parameter estimation of e-NRTL model for quaternary ammonium ionic liquids using Cuckoo Search. Chem. Eng. Res. Des. 1-9. doi:10.1016/j.cherd.2014.06.014

Jie, Z., Yan, X., Zhao, L., Worley, S.D., Liang, J., 2014. Eco-friendly synthesis of regenerable antimicrobial polymeric resin with N-halamine and quaternary ammonium salt groups. RSC Adv. 4, 6048. doi:10.1039/c3ra47147k

Kamlet, M.J., Abboud, J.L.M., Abraham, M.H., Taft, R.W., 1983. Linear solvation energy relationships. 23. A comprehensive collection of the solvatochromic parameters, .pi.*, .alpha., and .beta., and some methods for simplifying the generalized solvatochromic equation. J. Org. Chem. 48, 2877-2887. doi:10.1021/jo00165a018

Kang, J.W., Abildskov, J., Gani, R., Cobas, J., 2002. Estimation of Mixture Properties from First- and Second-Order Group Contributions with the UNIFAC Model. Ind. Eng. Chem. Res. 41, 3260-3273. doi:10.1021/ie010861w

Kaur, I., Kumari, V., Dhiman, P.K., 2011. Synthesis, characterization and use of polymer-supported phase transfer catalyst in organic reactions. J. Appl. Polym. Sci. 121, 3185-3191. doi:10.1002/app.33907

Kim, S.H., Anantpinijwatna, A., Kang, J.W., Gani, R., 2016. Analysis and modeling of alkali halide aqueous solutions. Fluid Phase Equilib. 412, 177-198. doi:10.1016/j.fluid.2015.12.008

Kolvari, E., Ghorbani-Choghamarani, A., Salehi, P., Shirini, F., Zolfigol, M.A., 2007. Application of N-halo reagents in organic synthesis. J. Iran. Chem. Soc. 4, 126-174. doi:10.1007/BF03245963 
Lee, L., Huang, H., 2002. Solubility of tetrabutylammonium bromide in benzene between $298.15 \mathrm{~K}$ and 323.15 K. J. Chem. Eng. Data 1135-1139.

Lindenbaum, S., Boyd, G.E., 1964. Osmotic and Activity Coefficients for the Symmetrical Tetraalkyl Ammonium Halides in Aqueous Solution at 25⒈ J. Phys. Chem. 68, 911-917. doi:10.1021/j100786a038

Lindenbaum, S., Leifer, L., Boyd, G.E., Chase, J.W., 1970. Variation of osmotic coefficients of aqueous solutions of tetraalkylammonium halides with temperature. Thermal and solute effects on solvent hydrogen bonding. J. Phys. Chem. 74, 761-764. doi:10.1021/j100699a014

Marcus, Y., 2008. Tetraalkylammonium Ions in Aqueous and Non-aqueous Solutions. J. Solution Chem. 37, 1071-1098. doi:10.1007/s10953-008-9291-1

Naik, S.D., Doraiswamy, L.K., 1998. Phase transfer catalysis: Chemistry and engineering. AIChE J. 44, $612-646$. doi:10.1002/aic.690440312

Najibi, H., Momeni, K., Sadeghi, M.T., 2015. Theoretical and experimental study of phase equilibrium of semi-clathrate hydrates of methane + tetra-n-butyl-ammonium bromide aqueous solution. J. Nat. Gas Sci. Eng. 27, 1771-1779. doi:10.1016/j.jngse.2015.11.002

Papaiconomou, N., Simonin, J.-P., Bernard, O., 2012. Solutions of Alkylammonium and Bulky Anions: Description of Osmotic Coefficients within the Binding Mean Spherical Approximation. Ind. Eng. Chem. Res. 51, 9661-9668. doi:10.1021/ie202954y

Piccolo, C., Shaw, A., Hodges, G., Piccione, P.M., O’Connell, J.P., Gani, R., 2012. A framework for the design of reacting systems with phase transfer catalysis. Comput. Aided Chem. Eng., Computer Aided Chemical Engineering 30, 757761. doi:10.1016/B978-0-444-59520-1.50010-5

Rozwadowska, M.D., 1985. Cyanohydrins as substrates in benzoin condensation. Tetrahedron 41, 3135-3140. doi:10.1016/S0040-4020(01)96667-0

Rueggeberg, W.H.C., Ginsbu'rg, A., Frantz, R.K., 1946. Benzyl Benzoate from Benzyl Chloride and Sodium Benzoate. Ind. Eng. Chem. 38, 207-211. doi:10.1021/ie50434a025

Sales-Cruz, M., Gani, R., 2003. A modelling tool for different stages of the process life, in: Computer Aided Chemical Engineering, Computer Aided Chemical Engineering. Elsevier, pp. 209-249. doi:10.1016/S1570-7946(03)80076-7

Samant, K.D., Singh, D.J., Ng, K.M., 2001. Design of liquid-liquid phase transfer catalytic processes. AIChE J. 47, 18321848. doi:10.1002/aic.690470814

Song, Y., Chen, C., 2009. Symmetric Electrolyte Nonrandom Two-Liquid Activity Coefficient Model. Ind. Eng. Chem. Res. 48, 7788-7797. doi:10.1021/ie9004578

Starks, C.M., 1971. Phase-transfer catalysis. I. Heterogeneous reactions involving anion transfer by quaternary ammonium and phosphonium salts. J. Am. Chem. Soc. 93, 195-199. doi:10.1021/ja00730a033

Starks, C.M., Owens, R.M., 1973. Phase-transfer catalysis. II. Kinetic details of cyanide displacement on 1-halooctanes. J. Am. Chem. Soc. 95, 3613-3617. doi:10.1021/ja00792a025

Talukdar, H., Kundu, K.K., 1991. Transfer energetics of tetraalkylammonium picrates in an aqueous ionic cosolvent system and the salt effect on hydrophobic hydration. J. Phys. Chem. 95, 3796-3800. doi:10.1021/j100162a065

Wen, W.-Y., Saito, S., Lee, C., 1966. Activity and Osmotic Coefficients of Four Symmetrical Tetraalkylammonium Fluorides in Aqueous Solutions at 25 1. J. Phys. Chem. 70, 1244-1248. doi:10.1021/j100876a044

Wu, Y., Friedman, H., 1966. Heats of solution of some tetraalkylammonium salts in water and in propylene carbonate and ionic enthalpies of transfer from water to propylene carbonate. J. Phys. Chem. 501, 2020-2024.

Yadav, G.D., Kadam, A.A., 2012. Atom-Efficient Benzoin Condensation in Liquid-Liquid System Using Quaternary Ammonium Salts: Pseudo-Phase Transfer Catalysis. Org. Process Res. Dev. 16, 755-763. doi:10.1021/op300027j 